\title{
„OBSIDIO VERONAE“ UND „PROELIUM APUD TiberIM" - Zum SELBSTVERSTÄNDNIS DES SPÄTANTIKEN KAISERTUMS ANHAND DER SChlachtenfriese des ArCus Constantini
}

\author{
Matthias SANDberg
}

Universität Potsdam

Zusammenfassung: Der Arcus Constantini gilt bis heute als eines der herausragendsten Monumente spätantiker Herrschaftsrepräsentation. An prominenter Stelle - die via triumphalis überspannend, gelegen zwischen dem Amphitheater, dem Palatin und dem Forum Romanum - vermittelt der Ehrenbogen seine ausgeklügelte und mehrdeutige politische Botschaft. Besonders bei der Betrachtung der Darstellung des Kaisers auf den constantinischen Schlachtenfriesen fällt die Entrückung des Imperators aus dem Kampfgeschehen sofort ins Auge. Zudem zeigt sich anhand eines Abgleiches der Schilderungen der Panegyriker mit den Kampfdarstellungen auf dem Constantinsbogen eine bemerkenswerte Divergenz zwischen Bild- und Textquellen hinsichtlich der Kampfbeschreibungen. Die Verschiedenheit der Berichte sowie die besondere Darstellung des Kaisers lassen sich anhand der Transformation des spätantiken Kaisertums schlüssig erklären; die Kampfdarstellungen des Constantinsbogens vermitteln die Besonderheiten der spätantiksakralisierten Herrschaftsideologie auf eindrucksvolle Art und Weise.

Schlüsselbegriffe: Constantinsbogen, kaiserliche Repräsentation, spätantike Herrscherideologie, Christianisierung, Triumphbogen.

ABSTRACT: Until today the Arcus Constantini counts as one of the most outstanding monuments of imperial representation of the late antiquity. In a prominent place - spanning over the via triumphalis, situated between the Amphitheatre, the Palatine and the Forum Romanum the arch communicates its elaborate and ambiguous political message. Regarding the modalities of how the emperor is represented on the friezes depicting the battle-scenes the displacement of the Imperators figure becomes immediately noticeable. Furthermore, it is apparent that there 
is a divergence between the picture- and the text-sources respectively the commentaries of the panegyrists concerning the battle-reports. The difference between both can be explained with the transformation of the late antique empire. The battle scenes of the arch of Constantine communicate the characteristics of imperial representation in late antiquity in an impressive manner.

Keywords: Arch of Constatine, imperial representation, late antique imperial ideology, Christianisation, triumphal arch.

$\mathrm{O}$ hne jeden Zweifel gehört Kaiser Constantin zu den herausragenden Augusti der Geschichte des spätantiken Imperium Romanum. Sein Name ist wie kein anderer mit der Hinwendung des römischen Imperiums zum Gott der Christen verbunden. ${ }^{1}$ Die Berichte über die Vision Constantins vor der Schlacht am Tiber, namentlich von Lactanz, Eusebius und einem heidnischen Panegyricus, belegen das Verlangen der Zeitgenossen, bei der Hinwendung Constantins zum christlichen Gott einen markanten Anfangspunkt auszumachen; der Höhepunkt des constantinischen Feldzuges gegen Maxentius, die folgenreiche Schlacht an der Milvischen Brücke, ist als jener Wendepunkt in die Geschichte eingegangen. ${ }^{2}$ Dabei hat man von der Tatsache auszugehen, dass der Ausgang der Schlacht, als der Augustus des Westens am 28. Oktober 312 an dem pons Milvius auf seinen Widersacher traf, keineswegs vorhersehbar war. Letztendlich verlor Maxentius Schlacht und Leben, Constantins göttlicher Schlachtenhelfer, so die christliche Deutung des Vorganges, hatte sich als probater Beistand erwiesen. ${ }^{3}$ Zur Würdigung des Sieges haben Senat und Volk von Rom, soweit die dedicatio der Inschrift,

1. Zur Hinwendung Constantins zum Christen-Gott, auch über Sol-Invictus, siehe: Eva LEHMEIER; Gunther Gotтlieb: «Kaiser Konstantin und die Kirche. Zur Anfänglichkeit eines Verhältnisses», in: Heinrich Schlange-Schöningen (Hrsg.), Konstantin und das Christentum, NWdF, Darmstadt 2007, 150170; Klaus Rosen: «Constantins Weg zum Christentum und die Panegyrici Latini», in: Giorgio Bonamente (Hrsg.), Costantino il Grande. Dall'antichità all'umanesimo, Macerata 1993, 853-863.

2. Lact. mort. pers. 44, 5. Eus. hist. eccl. 9, 9, 2; Eus. vita Const. 1, 28; Paneg. Lat. 12 2, 4. Dazu: HarTwiN BRAndT: «Die heidnische Vision Aurelians (HA, A 24, 2-8) und die christliche Vision Konstantins des Großen», in: Giorgio Bonamente; Gianfranco Paci (Hrsg.), Historiae Augustae Colloquium Maceratense, Bari 1995, 107-117; Peter Weiss: «Die Vision Constantins», in: Jochen Bleicken (Hrsg.), Colloquium zum Anlaß des 80. Geburtstags von Alfred Heuss, Kallmünz 1993, 143-169; neuerdings auch: Pedro BARCELó: Das Römische Reich im religiösen Wandel der Spätantike. Kaiser und Bischöfe im Widerstreit, Regensburg, 2013, 39-42.

3. Zur Bedeutung der Schlacht: Wolfgang KunofF: «Die Schlacht an der Milvischen Brücke. Ein Ereignis von weltgeschichtlicher Tragweite», in: Gregor Weber; Kay Ehling (Hrsg.): Konstantin der Große. Zwischen Sol und Christus. Mainz 2011, 10-20; zum Verlauf siehe: Bruno Bleckmann: Konstantin der Große, Reinbek bei Hamburg, 1996, 53-57; Oliver Schmitt: Constantin der Große, Stuttgart 2007, 150154. 
dem Augustus, anlässlich seiner im Jahr 315 bevorstehenden Decennalien, ein beeindruckendes Monument gewidmet; noch heute bezeugt der dreitorige Triumphbogen des Constantin an denkwürdiger Stelle - die via triumphalis überspannend, gelegen zwischen dem Amphitheater, dem Palatin und dem Forum Romanum - den Sieg des Flaviers an der Milvischen Brücke. ${ }^{4}$

Der Constantinsbogen ist ein ebenso herausragendes, wie mehrdeutiges Beispiel der Repräsentationskunst der späten römischen Kaiserzeit. ${ }^{5}$ Nicht nur, dass von dem christlichen Gott noch keine explizite Rede ist - einzig von göttlicher Eingebung spricht die Inschrift auf Vorder- und Rückseite der Attika -, auch Zeugnisse der paganen Religion finden sich zu Genüge. ${ }^{6}$ Zudem wird nicht ausschließlich auf die Person Constantins Bezug genommen, sondern auch auf die Ideale des römischen Kaisertums trajanischer, hadrianischer und marc-aurelianischer Prägung. Denn bei einem nicht eben geringen Teil des Bildschmucks am arcus Constantini handelt es sich um Spolien; als genuin spätantike Schmuckelemente bezeichnen lassen sich der umlaufende Fries oberhalb der beiden Seitendurchgänge, bestehend aus sechs größeren Reliefs und vier kleineren Eckreliefs, die Medaillons an den beiden Schmalseiten, die Postamentreliefs, die Bildelemente an den Schlusssteinen und in den Bogenzwickeln über den Haupt- und Seitenbögen, sowie die Reliefbüsten der Seitendurchgänge. ${ }^{7}$ Die Frage, warum ein Teil des Bildschmuckes nicht exklusiv constantinischer Provenienz ist, beschäftigt die einschlägige Literatur bis zum heutigen Tag. ${ }^{8}$ Der Autor der vorliegenden Studie hegt keinen Zweifel daran, dass dieser Umstand weder Ausdruck eines sinkenden Niveaus handwerklich-künstlerischen Vermögens, noch unbewusster Übernahme fremder Elemente sein kann; vielmehr hat man sich der Einsicht zu öffnen, dass gerade ein solches Monument dem Zweck dient, eine spezifische politische Botschaft zu vermitteln; dass die Verwendung fremder Elemente

4. CIL VI 1139 (P 3071, 3778, 4328, 4340) = CIL VI 31245 = ILS 694): „IMP(ERATORI) CAES(ARI) FL(AVIO) CONSTANTINO MAXimo / P(IO) F(ELICI) AUgusto S(ENATUS) P(OPUlus) Q(Ue) R(OMANUS) / QUOD INSTINCTU DIVINITATIS MENTIS / MAGNITUDINE CUM EXERCITU SUO / TAM DE TYRANNO QUAM DE OMNI EIUS / FACTIONE UNO TEMPORE IUSTIS / REM PUBLICAM ULTUS EST ARMIS / ARCUM TRIUMPHIS INSIGNEM dicavit." Die Einweihung des Bogens datiert Theodore Vern Buttrey: «The Dates of the Arches of „Diocletian“ and Constantine», in: Historia 32 (1983), 375-377 auf den 25. Juli 312.

5. Filippo CoARelli: Rom. Ein archäologischer Führer, Freiburg 1975, 165.

6. So finden sich beispielsweise in den Medaillons an den beiden Schmalseiten des Bogens Darstellungen von Sol und Luna und in den Bogenzwickeln sind Flussgottheiten dargestellt. Die beiden Schlachtenfriese warten mit Victorien in unmittelbarer Nähe des Kaisers auf. Vor diesem Kontext ist auch die Frage nach dem Opfergang Constantins auf dem Capitol zu erwähnen, dazu: JohannEs StrauB: «Konstantins Verzicht auf den Gang zum Kapitol», in: Historia 4 (1955), 297-313. Den von Frank KolB: Herrscherideologie in der Spätantike, Berlin 2001, 65 geäußerten Gedanken, der Wortlaut „instinctu divinitate “ meine keine Gottheit, sondern Constantins, von einer Gottheit eingeflößtes, inneres Numen hält der Autor dieser Untersuchung für durchaus bedenkenswert.

7. Siehe zur Benennung der Friese: Hans Peter L'Orange; Armin von Gerkan: Der spätantike Bildschmuck des Konstantinsbogens, Studien zur Spätantiken Kunstgeschichte 10, Berlin 1939, VII; Helmut PRÜCKNER, «Kaiser Konstantins Bilderbogen oder: Die Botschaft der Spolien», in: Thetis 15 (2008), 59 mit Anm. 2.

8. Siehe dazu Pedro Barceló: «Trajan, Maxentius und Constantin. Ein Beitrag zur Deutung des Jahres 312», in: Boreas 14/15 (1991/1992), 146-156, hier147 mit Anm. 7. 
eine eben solche Botschaft darstellt, ist kaum ernstlich in Zweifel zu ziehen. ${ }^{9}$ Die politische Botschaft, die sich dem Betrachter erst in der Gesamtschau der Bild- und Skulpturensprache des Monumentes mitteilt, lässt sich auf keine eindimensionale Formel reduzieren. Sie wird nur als Ganzes voll verständlich, erst recht vor dem Hintergrund der Tatsache, dass die genuin constantinischen Bilderwerke nicht bloß durch Spolien der Principes des beatissimum saeculum flankiert werden, auch die Gesichtszüge der guten Kaiser ließ Constantin teilweise zu seinen umarbeiten. ${ }^{10}$ Neben denen Constantins werden jedoch auch die Züge des Licinius in die Spolien eingearbeitet, ein Beleg freilich für die bis dato noch gültigen Prinzipien der Herrschaftsteilung, wie sie auch der numismatische Befund zulässt. ${ }^{11}$ Hier nun zeigt sich jedoch abermals die ambivalente Botschaft des Constantinsbogens. Neben der dargestellten concordia beider Augusti belegt die Inschrift auf der Attika, dass der Senat Constantin bereits kurz nach der Schlacht gegen Maxentius zum Maximus Augustus erhoben hat und damit eine Rangerhöhung gegenüber seinen Mitregenten Licinius und Maximinus Daia einherging. ${ }^{12}$ Constantins Kaisertum, wie es sich auf dem Bogen präsentierte, gehörte formal noch zum System der Tetrarchie, doch ließ es auch an der herausgehobenen Stellung des Maximus Augustus keinen Zweifel. Das constantinische Bildprogramm des Bogens griff nicht nur das Erbe der Kaiser des zweiten Jahrhunderts auf, sondern es suggerierte Komparativität. Diese eindrucksvolle Botschaft war nicht grundlos gewählt: Die Tatsache, dass Constantin durch seine konsequente Missachtung der durch Diocletian geschaffenen Ordnung maßgeblich an der Erosion des Tetrarchates beteiligt war - immerhin hatte seine Usurpation und deren nachträgliche Anerkennung durch Galerius den Präzedenzfall für die Selbsterhebung des Maxentius geschaffen - sowie der Umstand, dass Constantin nicht über einen äußeren Feind, sondern in einem Bürgerkrieg ex sanguine Romano gesiegt hatte, lassen eine Einreihung in die Linie der guten Kaiser des zweiten Jahrhunderts durchaus sinnfällig erscheinen. ${ }^{13}$ Trajan,

9. Ein großer Teil der Ergebnisse zu denen Marion Roenmer: Der Bogen als Staatsmonument. Zur politischen Bedeutung der römischen Ehrenbögen des 1. Jhs. $n$. Chr.. München, 1997 gelangt ist, hat auch im 3. und 4. Jahrhundert durchaus noch Relevanz; freilich mit Constantin in christlicher Hinsicht umgedeutet.

10. PrüCKNer, Konstantins Bilderbogen, 60. Die trajanischen Elemente finden sich in den beiden Reliefs am Hauptdurchgang, an den Schmalseiten des Attikageschosses und ebenso sind die acht der Attika vorgestellten Statuen trajanischer Herkunft, sie stammen wahrscheinlich aus dem Hof des Trajansforums. Die acht Tondi über den beiden kleineren Durchgängen zu beiden Seiten des Hauptdurchganges sind als hadrianisch anzusprechen und die acht Reliefs auf der Vorder- und auf der Rückseite der Attika sind Marc Aurel zuzuordnen. Aussagen über die Herkunft der beiden letztgenannten Bildkomplexe lassen sich ungleich schwerer treffen, die marc-aurelischen Spolien stammen wohl von einem verlorenem Ehrenbogen, für den Ursprung der hadrianischen Tondi gibt es keinen Anhaltspunkt. Dazu: PrüCKNER, Konstantins Bilderbogen, 60.

11. Man bedenke die Concordia-Münzprägungen für beide Augusti im Osten und Westen des Reiches, namentlich in Trier, Ticinum, Aquleia, Nicomedia, Antiochia und Sirmium aus den Jahren 320-322. Kolb, Herrscherideologie, 61-62.

12. Zum Wortlaut der Inschrift siehe Anm. 5. Dazu: KоLв, Herrscherideologie, 61.

13. Vor diesem Hintergrund ist auch die constantinische Propaganda zu erwähnen - allem voran die des Eusebius - wonach die Herrschaft des Maxentius für Rom nicht nur repressiv, sondern gar äußerst blutig gewesen sei. Beispiele finden sich bei Eus. hist. eccl. 8, 14 und Eus. vita Const. 1, 33-36, die das 
Hadrian und Marc Aurel wurden Constantin zu Garanten und Idealen seines Kaisertums. ${ }^{14}$ Gerade dies macht die Besonderheit und die politische Brisanz des Bildschmuckes des arcus Constantini aus. ${ }^{15}$ Der Bogen ist die baulich manifeste Form des constantinischen Kaisertums und eine Regierungserklärung, eben nicht bloße Memoria anlässlich des Sieges über Maxentius. Schließlich erinnert der epigrafische Befund - an den beiden Seiten des Hauptdurchgangs finden sich die auf Trajan bezogenen Termini Liberatori Urbis und Fundatori Qietis - durchaus an augusteische Herrscherideologie, man denke etwa an das Bildprogramm der Ara pacis Augustae oder die Aussagen der Res Gestae DiviAugusti etwa aufdem Monumentum Ancyranum. ${ }^{16}$ Diese für Historiker wie Archäologen bis heute reizvollen Tatsachen lassen eine Beschäftigung mit dem Bildschmuck des Bogens als lohnendes Interesse erscheinen.

\section{Die constantinischen Friese an der Südseite}

Der reiche Relief-,,Medaillon-und Skulpturenschmuckdes arcus Constantini besteht sowohl aus constantinischen Elementen, als auch aus Spolien des 2. Jahrhunderts. Für die vorliegende Untersuchung von herausgehobener Bedeutung ist der historische Zyklus der constantinischen Reliefs, die sich über den Rundbögen um den gesamten Ehrenbogen erstrecken. Diese Friese markieren den Kristallisationspunkt aller inhaltlichen Aussagen des Bogens; sie sind nicht nur Regest des Oktobers 312, sie bilden das Fundament kaiserlicher Selbstdarstellung am Constantinsbogen.

Bild eines mordenden, vergewaltigenden und unfähigen Tyrannen entwerfen. Dieses Bild ist erst durch die moderne Forschung als unzutreffend zurückgewiesen worden. Bei Lact. mort. pers. 26-28 findet sich sogar eine vorsichtig-wohlwollende Beschreibung der Herrschaft des Maxentius. Zur historischen Einordnung der Herrschaft des Maxentius und zur Negativ-Propaganda siehe: Edmund GroAg: «Maxentius», in: RE XIV, 2, Stuttgart 1930, 2417-2484. - Ausführlich zu Constantins Usurpation am 25. Juli 306 siehe: Kolв, Herrscherideologie, 59-60. Außerdem: Тімотну Barnes: «Christentum und dynastische Politik (300-325) », in: Francois Paschoud; Joachim Szidat (Hrsg.), Usurpationen in der Spätantike, in: HistoriaEinzelschriften 111, Stuttgart 1997, 99-109; Klaus BringmanN: «Die konstantinische Wende. Zum Verhältnis von politischer und religiöser Motivation», in: HZ 260 (1995), 21-47.

14. PRÜCKNER, Konstantins Bilderbogen, 60.

15. Die Tatsache, dass es sich beim constantinischen Feldzug gegen Maxentius um einen Triumphzug handelte und es daher keinen „echten“ Triumph geben konnte, belegt abermals ein Hinweis auf die Inschrift die von "arcus trumphis insignem" spricht. Die Verwendung des Plurals erklärt sich, liest man die Inschrift als Verweis auf die Größe der gesamten Taten Constantins, sie waren ganz einfach triumphal. Auch die Betonung der „iustis armis" beweist das Bewusstsein für die delikate Situation. Dazu: PrüCKNER, Konstantins Bilderbogen, 63 mit Anm. 15; Joseph ENGEMANN: «Der Konstantinsbogen», in: Alexander Demandt, Josef Engemann (Hrsg.): Konstantin der Große. Imperator Caesar Flavius Constantinus, Ausstellungskatalog, Mainz 2007, 85-89, hier 86. Dass die Kampfreliefs nach Norden, also zur der Stadt abgewandten Seite zeigen, könnte der Tatsache geschuldet sein, dass es sich um die Ehrung einer victoria civilis handelt.

16. Zum constantinischen Kaiserkult siehe: JOHANnEs KarayanNOPULOS: «Konstantin der Große und der Kaiserkult», in: ANTONiE Wlosok (Hrsg.), Römischer Kaiserkult, WdF 372, Darmstadt 1978, 485-508. - Zur Ara Pacis siehe: Alexander Mlasowsky: Ara Pacis. Ein Staatsmonument des Augustus auf dem Marsfeld, Mainz 2010. - Zum Monumentum Ancyranum siehe: EKKehard Weber (Hrsg.): Res Gestae Divi Augusti. Meine Taten, Düsseldorf 2004. 
Die Geschichte der Friese lässt sich nicht ausnahmslos rekonstruieren; dazu passt der Quellenbefund, wonach sich selbst für das Altertum kein schriftlicher Beleg finden lässt. ${ }^{17}$ Wie seine Geschichte ist auch der Triumphbogen selbst nicht gänzlich lückenlos. Verantwortlich dafür zeichnen die Metalldiebe des Mittelalters und der Renaissance. Sie haben, indem sie sich durch die Quaderwände an das Metall der Klammern und Dübel heranarbeiteten, den Reliefs zum Teil erheblichen Schaden zugefügt, sogar ganze Blöcke wurden herausgebrochen; 1597 wurde die Wegnahme eine der acht Frontsäulen durch Papst Clemens VIII. veranlasst. ${ }^{18}$ Zudem war der Bogen mehrfach in andere Bauten integriert worden, so diente er als Wehrturm für einen frühmittelalterlichen Konvent, hat als Kastell der Frangipani herhalten müssen und gehörte im Spätmittelalter womöglich zu einem nach ihm benannten Kirchenbau. ${ }^{19}$ In der Frühen Neuzeit ist es vor allem dem päpstlichen Engagement geschuldet, dass der Bogen - durch mutwillige Beschädigungen sowie natürliche Erosion bereits stark in Mitleidenschaft gezogen - instand gesetzt und von Erdreich befreit wurde. ${ }^{20}$

Für die als constantinisch geltenden Friese haben von Gerkan und L'Orange deren einheitliche Entstehungszeit und künstlerische Zusammengehörigkeit - auch vor dem Hintergrund abweichender handwerklicher Techniken und Differenzen hinsichtlich der künstlerischen Marnier - schlüssig belegt. ${ }^{21}$ Es wurde der Bohrer zur Gestaltung der Oberfläche ebenso verwandt wie der Meißel. ${ }^{22}$ Die Friese sind unter Maßgabe eines leitenden Künstlers von einer Werkstatt verfertigt worden, vermutlich unter Zeitdruck, denn eingedenk der unterschiedliche Stile und dem gelegentlich unfertigen Charakter der Darstellungen lässt sich eine parallele Bearbeitung der Marmorquader durch mehrere Bildhauer ableiten; ${ }^{23}$ wohl zur selben Zeit hat ein Künstler innerhalb der Spolien-Reliefs die Gesichtszüge der Kaiser zu denen Constantins und Licinius' umgearbeitet. ${ }^{24}$ Die künstlerisch-technische Variation der Friese dürfte sich aus zwei Tatsachen heraus erklären lassen: Erstens bestimmen

17. L'Orange, Der spätantike Bildschmuck, 1.

18. Ebd. 1-2. Ebd.

19. Von der Verbauung des Bogens zeugen heute noch die in die Reliefs gehauenen Lager für Balken:

20. Im ausgehenden 15. Jahrhundert - genauer im Jahr 1498 - sind den Skulpturen scheinbar wieder die Originalköpfe aufgesetzt worden. Papst Paul III. sorgte, anlässlich des triumphalen Einzuges Kaiser Karls V. im Jahre 1536, für das Abtragen des Erdreiches, um einen großen Teil der Säulenpostamente wieder freizulegen. 1570 wird auf Geheiß Papst Pius V. eine Ausbesserung der Beschädigungen durch Pflanzenbewuchs und Metallraub vorgenommen. Eine umfassende Instandsetzung erfolgte 1733 durch Clemens XII. Anfang des 19. Jahrhundert fanden abermalig Restaurationsarbeiten im Obergeschoss des Bogens statt und 1938 wurden anlässlich des Besuches Adolf Hitlers weitere Instantsetzungsarbeiten vorgenommen. Dazu: L’Orange, Der Spätantike Bildschmuck, 2-3.

21. L'Orange, Der spätantike Bildschmuck, 34.

22. Ein Beispiel für die enge Vermischung beider Techniken liefern der Ingressus- und der Oratio-Fries: Ebd. 34, 35.

23. Die verschiedenen Arbeitsmanieren - eine grob-naturalistische sowie eine plastisch-ästhetische Darstellungsweise - äußern sich beispielsweise in den Victorien der Obsidio und des Proelium, jedoch bei gleichbleibendem handwerklichen Ausdruck. Dazu: L’Orange, Der spätantike Bildschmuck, 32.

24. L'OrAnge, Der spätantike Bildschmuck, 33. 
die unterschiedlichen Themen der Friese ihre spezifische Darstellungsform und zweitens müssen die Friese als Werke verschiedener Bildhauer einer Werkstatt angesehen werden, da nicht nur Gewandungen, Gesichtszüge und Idealfrisuren auf den verschiedenen Fries-Abschnitten bisweilen fast identisch dargestellt werden, sondern auch die Arbeitstechniken der Schulung einer Werkstatt zuzuordnen sind.$^{25}$ Als ebenso einheitlich wie die Urheberschaft der Friese hat deren Entstehungszeit zu gelten; sie ist identisch mit der Bauzeit des Bogens: Der Terminus post quem ist der 28. Oktober 312, der Terminus ante wird durch die Votivinschriften der Vota Soluta und Vota Suscepta oberhalb der beiden Seitendurchgänge (Nordseite: votis $X$ votis $X X$; Südseite: sic $X$ sic $X X)$ und deren Bezug auf die 316 anstehenden Decennalien Constantins belegt, deren Feiern im Vor- und im Jubiläumsjahr selbst stattfinden konnten. ${ }^{26}$ Übereinstimmend mit Constantins Rom-Aufenthalt vom 21. Juli bis zum 27. September 315, dem numismatischen Befund mit der Angabe adventus Augusti für dieses Jahr und in Kenntnis des 25. Juli 306, als Constantin in Eboracum zum Augustus erhoben wurde, lässt sich der Weihetag des Monumentes auf den 25. Juli 315 datieren. $^{27}$

Neben der handwerklich-gestaltlichen Uniformität der Friese bietet sich auch deren inhaltliche Zusammengehörigkeit als Beleg für die exklusiv constantinische Provenienz an. Der umlaufende Fries - sechs große sowie vier kleinere Eckreliefs - stellt einen zusammenhängenden Zyklus dar;seine Zählung beginnt auf der westlichen Schmalseite und verläuft dann nach rechts um den gesamten Bogen herum. Die Szenerie auf dem Constantinsbogen beginnt auf der westlichen Schmalseite mit der Profectio, dem Aufbruch des Heeres, zu erkennen an dem Durchschreiten eines Bogens, noch ohne den Kaiser. ${ }^{28}$ Auf der Südseite des Bogens folgen die Belagerung einer befestigten Stadt namentlich Veronas (Obsidio Veronae) - mit der deutlichen Hervorhebung der Figur des Kaisers und die Schlacht an der Milvischen Brücke (Proelium apud Tiberim), die sich ebenfalls durch die Betonung des Kaisers auszeichnet. Darauf folgend wird auf der östlichen Schmalseite der Adventus des Siegers in Rom dargestellt (Ingressus), wobei der Kaiser auf dem von einer Victoria geführten Wagen durch die Porta Flaminia fährt. Schließlich komplettieren zwei Friedensszenen - die Rede des Siegers im Akklamationsgestus auf dem

25. Vgl. zum Beispiel die Ausarbeitung des Felsens im Reliefzyklus, die sich in identischer Form in den als constantinisch belegten Bogenzwickeln wiederfinden lässt; ebenso verhält es sich mit den Darstellungen der Flussgötter. Einen weiteren Beleg liefert die Betrachtung des charakteristischen Faltenwurfes der Tuniken der Hornbläser auf den constantinischen Kampfdarstellungen. Dazu: L'Orange, Der spätantike Bildschmuck, 36-37.

26. Die Frage nach der Entstehungszeit und Einheitlichkeit des Bogens kann mit L'Orange, Der spätantike Bildschmuck, 4-51 als abgeschlossen gelten. Zu Recht stellt diese Arbeit bis heute das deutschsprachige Standardwerk zum Constantinsbogen dar.

27. Siehe z.B.: Theodore Vern Buttrey: «The Dates of the Arches of "Diocletian“ and Constantine», in: Historia 32 (1983), 375-377; ebenso: L'OrANGE, Der spätantike Bildschmuck, 33.

28. Auch auf der Trajanssäule tritt der Kaiser erst auf dem Höhepunkt der Handlungen auf, bei der Darstellung des gerüsteten und aufbrechenden Kriegszuges fehlt er, wie auf dem Constantinsbogen. Die Benennung der Friese innerhalb der vorliegenden Untersuchung folgt der etablierten Terminologie. 
Forum Romanum und das kaiserliche Donativ (Oratio und Liberalitas Augusti) - auf der Nordseite des Bogens die Erzählung. ${ }^{29}$ Die Bewegung der Kampf- und Prozessionsdarstellungen verläuft, beginnend auf der westlichen Schmalseite, stets von links nach rechts in Profilansicht. Dabei erinnert die kontinuierliche Darstellungsform an die Reliefbänder der Säulen des Marc Aurel und des Trajan, deren bildliche Darstellungen sich in einer fortgesetzten Spirale bis auf den - wörtlichen - Höhepunkt entwickeln. ${ }^{30}$ Einzig die beiden Friese an der Nordseite des Bogens, die Oratio und die Liberalitas konzentrieren sich in ihrer nahezu bewegungslosen Symmetrie in Frontalansicht auf die zentrale Figur des Kaisers; die Komposition unterliegt einer anderen Darstellungsabsicht: Die imperatorische Gewalt des Kaisers - deutlich auf den beiden Schlachtenszenen auf der Südseite des Bogens zu erkennen - tritt anlässlich der Wiederherstellung der staatlichen Ordnung in den Hintergrund; die kaiserliche Amtstracht anlässlich der Ansprache auf dem Forum und die Verteilung von Geschenken durch den in die Toga gewandeten Kaiser sind die deutlichsten Signale für die reinstallierte Normalität. Zusammenfassend kann festgehalten werden, dass der Relief-Zyklus am Constantinsbogen aufgrund seines Aufbaus als typischer Vertreter eines kontinuierlichen historischen Triumphalreliefs gelten kann. ${ }^{31}$

\section{Zur Beschreibung des Kampfes auf dem Fries „Obsidio Veronae“}

Auf der Südseite des Bogens erstreckt sich oberhalb des linken Seitendurchganges der vergleichsweise gut erhaltene Fries mit der Darstellung der Belagerung einer Stadt über eine Länge von 5,39 m mit den Seitenstreifen und einer Frieshöhe von 0,92 m; die größte Reliefausladung beträgt $0,15 \mathrm{~m}$ [Abb. 1, 2, und 3]. ${ }^{32}$ Der Reliefblock mit seiner oberen Rahmenleiste ist aus zwei Reihen übereinandergelegter Blöcke gehauen, die drei unteren Blöcke sind 0,56 m hoch, die Höhe der vier oberen Blöcke beträgt 0,46 m. Der Fries wird nach unten durch ein Gesims der unter dem Relief befindlichen Blockschicht begrenzt; nach oben wölbt sich der Grund 0,04 m hervor. ${ }^{33}$ Nach

29. L'Orange, Der spätantike Bildschmuck, 37. - Im Hintergrund der Orations-Szene finden sich die Basilica Iulia, das Tetrarchenmonument, sowie die Bögen des Septimius-Severus und des Titus. Der Kaiser sitzt, flankiert von Sitzstatuen des Marc Aurel und des Hadrian.

30. Martin Beckmann: «The 'Columnae Coc(h)lides' of Trajan and Marcus Aurelius», in: Phoenix 56 Nr. 3/4 (2002), 348-357; Ritchie Pogorzelski: Die Traianssäule in Rom. Dokumentation eines Krieges in Farbe, Mainz 2012; Mark Wilson Jones: «One Hundred Feet and a Spiral Stair. The Problem of Designing Trajan's Column», in: Journal of Roman Archaeology 6 (1993), 23-38; MAX WeGNER: «Die kunstgeschichtliche Stellung der Marcussäule», in: Jahrbuch des Deutschen Archäologischen Instituts 46 (1931), 61-174.

31. L'OrAnge, Der spätantike Bildschmuck, 41.

32. Gerhard Koeppel: «Die historischen Reliefs der römischen Kaiserzeit VII. Der Bogen des Septimius Severus, die Decennalienbasis und der Konstantinsbogen», in: Bonner Jahrbücher 190 (1990), 1-64, hier 43; L’Orange, Der spätantike Bildschmuck, 60; Abb. 10.

33. Koeppel, Die historischen Reliefs, 43. 


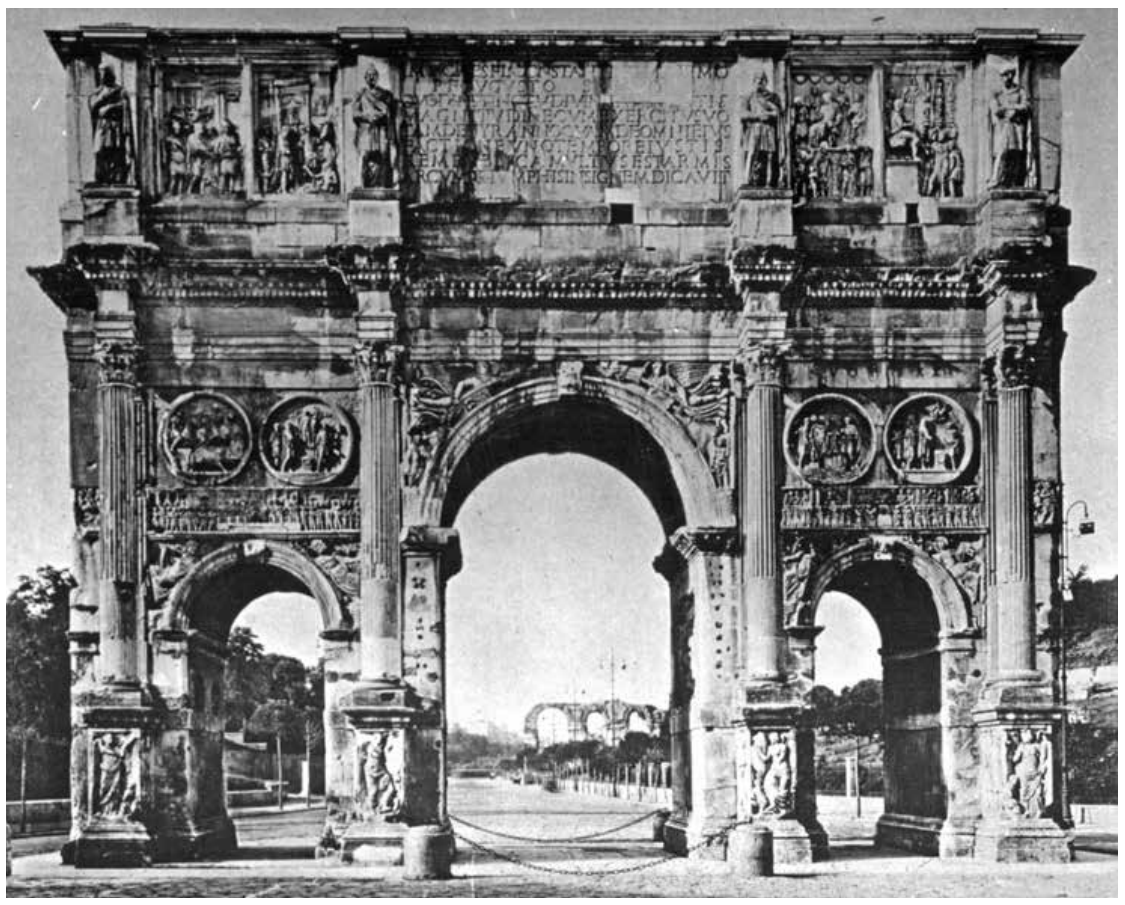

Abb. 1. Rom, Constantinsbogen, Gesamtansicht, aus: Antonio GiUliano: Arco di Constantino, Mailand 1955, Abb. 1

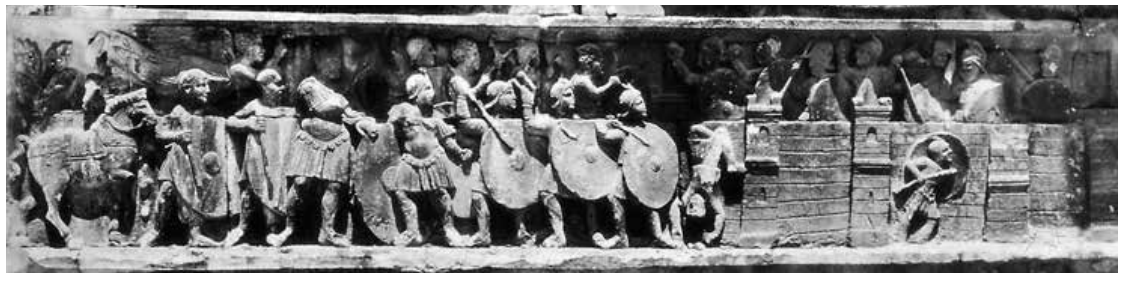

Abb. 2. Rom, Constantinsbogen, Schlachtenfries oberhalb des linken Seitendurchganges an der südlichen Schmalseite, Obsidio Veronae, aus: EMANUel MAYER: Rom ist dort, wo der Kaiser ist. Untersuchungen zu den Staatsdenkmälern des dezentralisierten Reiches von Diocletian bis zu Theodosius II., Mainz 2002. Taf. 38-2

oben und nach rechts wird die Reliefschicht von einem Karnies begrenzt, wobei die Figuration bisweilen den Reliefrand überlagert, so der Lorbeerbaum auf der linken und die Stadtmauer auf der rechten Seite. Auf der linken Seite ist der Rahmen zudem fast gänzlich weggebrochen. ${ }^{34}$ Der Grund des Reliefs 


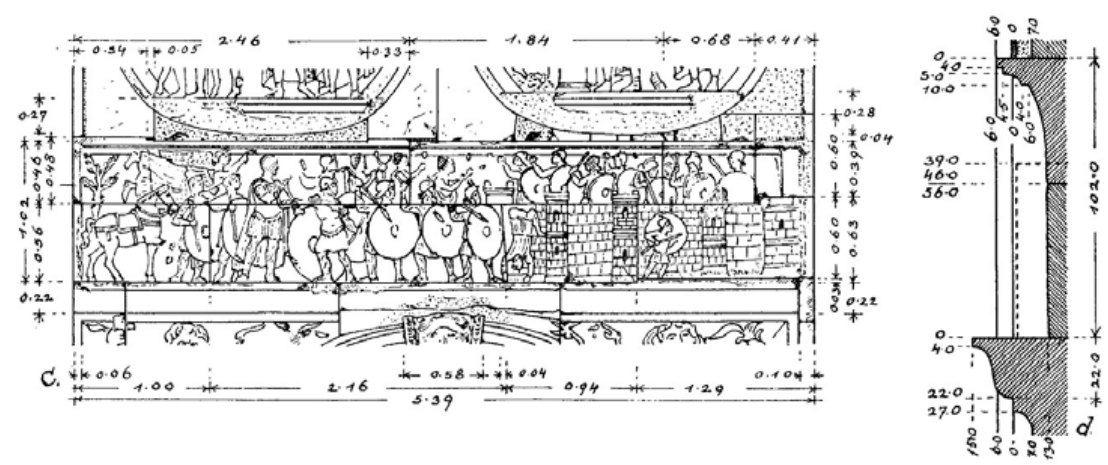

Abb. 3. Rom, Constantinsbogen, Umzeichnung und Schnitt, Obsidio Veronae, aus: HANS Peter L'Orange; Armin Von Gerkan: Der spätantike Bildschmuck des Konstantinsbogens, Studien zur Spätantiken Kunstgeschichte 10, Berlin 1939, Abb. 11

zeichnet dich durch eine starke Wellierung aus. Auch finden sich Spuren von Unfertigkeit, so beispielsweise der plötzliche Abbruch der Quaderstruktur zwischen den beiden den Belagerern zugewandten Türmen der Stadt oder die nur schemenhafte Ausarbeitung der Füße der vor der Stadt befindlichen nach rechts eilenden Figur. ${ }^{35}$ Auf dem Fries wechseln sich der Meißel und der Bohrer ab, während ersterer die Oberfläche gestaltete, diente der Bohrer zur filigranen Ausarbeitung der Soldatenfiguren, etwa zur Gestaltung der Lappenstruktur der soldatischen Panzer. ${ }^{36}$

Die Komposition des Obsidio-Frieses lässt sich in zwei Teile gliedern: Auf der linken Seite - gruppiert um die überlebensgroße Figur des Kaisers - zeigt es die Truppen der Angreifer, auf der rechten Seite die in einer Stadt belagerten Verteidiger; wobei ein vorpreschender Soldat die Szenerie im Vordergrund der Mauer beherrscht. Die Angreifer umzingeln dabei nicht etwa die eingeschlossene Stadt, sondern sind in der Ebene der Stadt in einer Doppelreihe hintereinander gestaffelt. Der Kampf an der Stadtmauer stellt das Zentrum des Geschehens dar, wenngleich er nicht die einzige Kampfhandlung ist. Die Komposition liefert mithin keine verschlungene Erzählung von individuellen Kampfszenen; einzig die vordersten Angreifer und Verteidiger sind die Träger des Kampfgeschehens, abermals freilich mit Ausnahme des vorstürmenden Angreifers, der ebenfalls den Kampf der Verteidiger von den Mauern herab auf sich zieht und somit die zweite Kampfdarstellung liefert.

Das Zentrum der angreifenden Truppen bildet die wuchtige nach rechts gewandte Gestalt des unbewaffneten und unbehelmten Kaisers - er überragt die Soldaten um etwa ein Fünftel ihrer Größe [Abb. 4]. Er und seine Leibwache bleiben vom Kampfgeschehen unberührt. Dabei korreliert die Größe des

35. L'Orange, Der spätantike Bildschmuck, 60.

36. Ebd. 


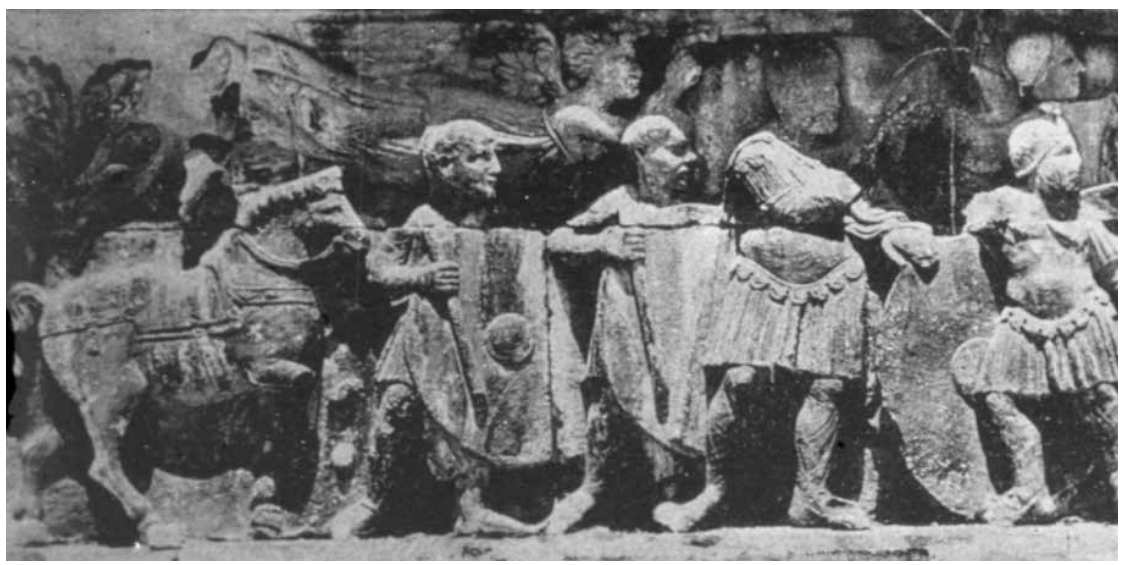

Abb. 4: Rom, Constantinsbogen, Relief, Ausschnitt der Kaisergruppe, Obsidio Veronae, aus: Antonio Giuliano: Arco di Constantino, Mailand 1955, Abb. 37

Kaisers mit der Enormität seines Schildes: ein Rundschild mit Umbo. Die schon fast unbewegte Köpersprache der Kaiserfigur unterstreicht die Distanz zum Kampfgetümmel. Anders als beispielsweise die angreifenden Soldaten der unteren Reihe, deren angestrengte Beinhaltung den Einsatz von Schild und Lanze anzeigt, ist der Kaiser betont zurückgenommen: Das rechte Bein ist nur leicht aufgesetzt, sein linker Arm liegt auf dem stehenden Schild und er hebt die rechte Hand im Sol-Gestus in Richtung des Kampfgeschehens. ${ }^{37}$ Der Kaiser auf dem Obisidio-Fries, auch das unterstreicht seine enorme Gestalt, stellt den imperatorischen Lenker des Kampfgeschehens dar. Wie die speertragenden Soldaten trägt die Kaiserfigur die langärmelige Tunica, eine Hose (Bracae) sowie flache Schuhe. Ergänzt wird die Kaiserfigur durch den nach unten abgerundeten Muskelpanzer mit verzierten Pteruges und den Laschen der subarmalis. Das paludamentum wird auf der rechten Schulter von einer Fibel gehalten und bedeckt die linke Brust, sowie die linke Schulter und den linken Arm. ${ }^{38}$ Im Unterschied zu den anderen Friesen wurde der Kopf der Kaiserfigur des Obsidio-Frieses als einziger aus dem Quader gehauen; die Köpfe der Kaiser der übrigen Reliefs sind extra gearbeitet worden [Abb. 5]. ${ }^{39}$ Die heute noch vorhandenen Kopffragmente geben ein ausdrucksstarkes Profil eines großen runden Kopfes mit markanten Zügen und glatten Haaren, eine kräftigen Nase und ein vorstechendes Kinn zu erkennen. Bei der Figur handelt es sich um Kaiser Constantin.

37. Koeppel, Die historischen Reliefs, 44.

38. Ebd.

39. L'Orange, Der spätantike Bildschmuck, 53, 61. 


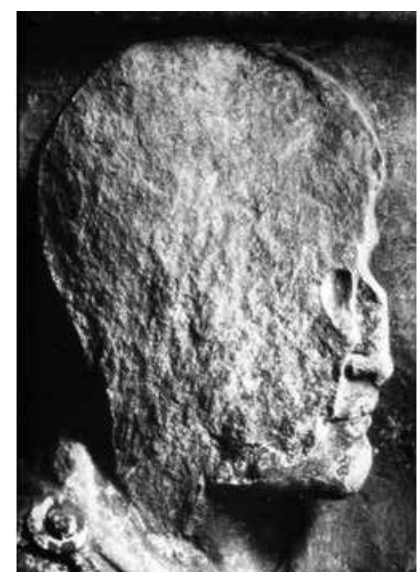

Abb. 5. Rom, Constantinsbogen, Detail Kaiserkopf, Obsidio Veronae, aus: Mitteilungen des Deutschen Archäologischen Instituts, Römische Abteilung (=Bullettino dell'Istituto Archeologico Germanico, Sezione Romana) 105 (1998), Taf. 53-4

Vom Lorbeerbaum des äußeren linken Bildrandes kommend, schwebt über dem kaiserlichen Gefolge eine mit einem langen gegürteten Chiton bekleidete Victoria auf die Kaiserfigur zu; die rechte Schulter und die rechte Brust sind unbedeckt und die Füße teilweise weggebrochen [Abb. 4] ${ }^{40}$ Der hohe Haarschopf ist im Nacken gebunden. In der Linken unter der Brust hält sie ein Tropaion, in der Rechten den teils weggebrochenen Lorbeerkranz für den Kaiser. Sie ist die einzige Figur, deren Größe der des Kaisers entspricht.

Das Gefolge des Kaiser besteht aus drei Figuren: Zwei unbehelmte Soldaten und ein Pferd, das von der linken Soldatenfigur am Zaumzeug geführt wird [Abb. 4]. Die sehr großen Schilde mit Umbo verraten, dass es sich bei den beiden Soldaten-Figuren um die kaiserliche Leibwache handelt. ${ }^{41}$ Sie tragen eine langärmelige gegürtete Tunica, die Bracae und flache Schuhe mit Riemen. ${ }^{42}$ Ergänzt wird ihre Gewandung um das auf der rechten Schulter von einer Fibel gehaltene Sagum. ${ }^{43}$ Die Beinhaltung gleicht der des Kaisers, wenngleich sie auch geringfügig angestrengter ist; mit der rechten Hand fassen sie die Lanze bei der linken Figur ist sie kurz über der Hand weggebrochen -, die linke Hand hält den Schild. Links hinter den Protectores Augusti wartet das kaiserliche Pferd mit angewinkeltem rechtem Vorderlauf, von dem heute ein großer Teil fehlt. Sein massiger, gedrungener und im Vergleich zu den Soldatenfiguren disproportionaler Körper zeichnet sich durch den massiven aderlosen Kopf mit frisierter Mähne und die hölzerne Bewegung seiner Glieder aus. Das reich

40. Koeppel, Die historischen Reliefs, 43-44.

41. L'Orange, Der spätantike Bildschmuck, 62.

42. Koeppel, Die historischen Reliefs, 43.

43. L'Orange, Der spätantike Bildschmuck, 53, 62. 
verzierte Geschirr und der große Sattel geben seine Funktion als Reittier des Kaisers zu erkennen. ${ }^{44}$

Unmittelbar rechts vor der Figur des Kaisers ist ein frontal stehender Soldat zu erkennen, den man aufgrund seines Muskelpanzers und seines verzierten Helmes wohl als Offizier anzusprechen hat [Abb. 6]. ${ }^{45}$ Die stark abgestoßene und erodierte Figur trägt ebenfalls die langärmelige Tunica und Bracae; sein Muskelpanzer läuft wie der des Kaisers nach unten in einen gebogenen Rand aus und die Pteruges sind wie die der Kaiserfigur mit Rosetten verziert, unter denen die Lappen der subarmalis das Becken umgeben. ${ }^{46}$ Anders als bei der Soldatengruppe vor ihm bedeckt sein Rundschild die zum Reliefgrund weisende Flanke und wir erkennen dessen Innenseite. Sein heute nur fragmentarisch erhaltender rechter Arm hebt zu einem mächtigen Wurf an; von seinem Speer ist nur noch ein Teil der Spitze auf dem Muskelpanzer zu erkennen. ${ }^{47}$ Der spiralig verzierte Helm mit Stirnbügel und Wangenklappen hat einen weit auslaufenden Nackenschutz; oberhalb des Stirnbügels waren ursprünglich Hörner angebracht, von denen Reste am Hals der sich über ihm befindlichen Figur zeugen. ${ }^{48}$ Die Hörner können - eingedenk der gallischen Herkunft der constantinischen Kerntruppen - als Beleg für ihre Zugehörigkeit zu den

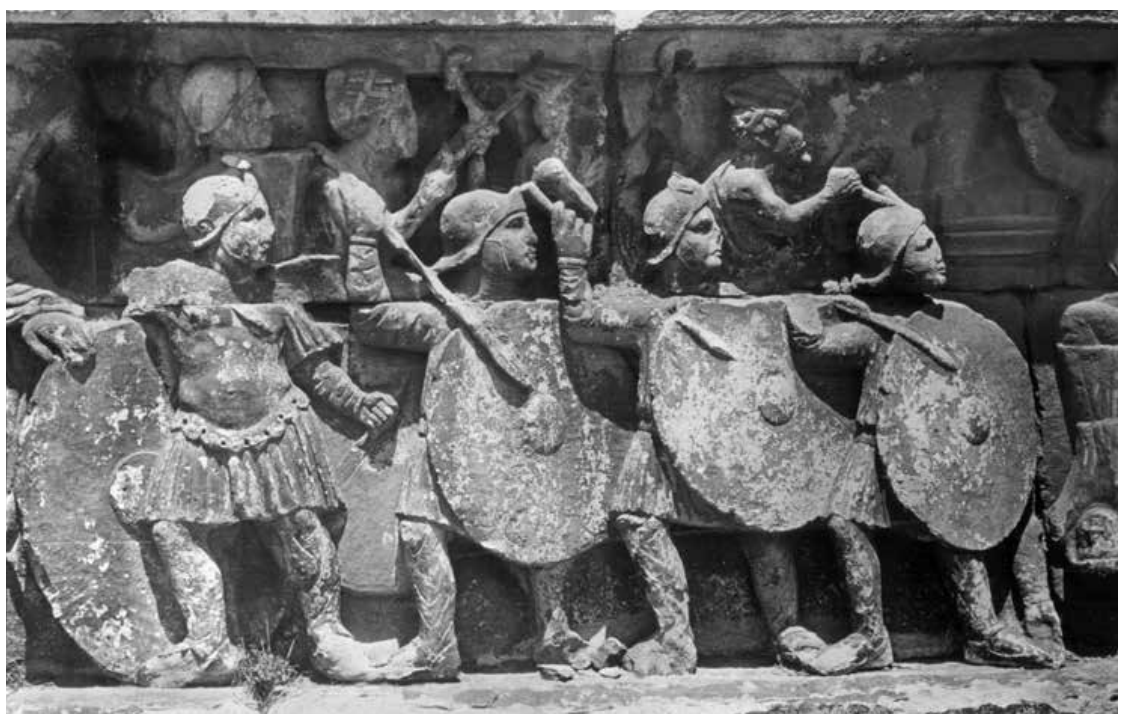

Abb. 6. Rom, Constantinsbogen, Relief, Ausschnitt Angreifer, Obsidio Veronae, aus: ANTONIO Giuliano: Arco di Constantino, 1955 Mailand, Abb. 37 l. u.

44. Koeppel, Die historischen Reliefs, 44.

45. L'Orange, Der spätantike Bildschmuck, 53, 63.

46. Koeppel, Die historischen Reliefs, 46.

47. Ebd.

48. Ebd. 
Cornuti gesehen werden. Wenn das der Fall ist, stellt der Constantinsbogen die erste Quelle zur Aufnahme dieser gallischen Truppen in römische Dienste dar, denn ein schriftlicher Beleg für die Cornuti wird für den Historiker erstmals zwischen 425 und 430 in der Notitia dignitatum greifbar. ${ }^{49}$

Rechts vor dem Offizier schließt sich der Block der angreifenden Soldaten an [Abb. 6]. Die untere Ebene der gestaffelten Doppelreihe besteht aus drei speertragenden Soldaten in Wurfhaltung, oberhalb dieser Truppen setzen drei Bogenschützen zum Abschuss ihrer Pfeile an; links hinter ihnen und oberhalb des Offiziers ist in derselben Ebene ebenfalls ein Lanzenträger zu erkennen. Zwei Typen von Kampftruppen sind unter den Angreifern der Obsidio zu finden: Die speertragenden Soldaten sowie der fernkämpfende Typus der Sagittarii. Die Speerträger - wie alle Angreifer kämpfen sie zu Fuß - tragen lange gegürtete Tunicae bis an das Knie, Bracae und flache Schuhe, gelegentlich mit Riemen. Außerdem tragen sie den Helm vom attischen Typus mit aufgerolltem Rand und Wangenklappen, der bis auf die fehlende Verzierung in etwa dem Helm des linken Cornuti-Offiziers entspricht..$^{50}$ Die Soldaten des lanzentragenden Typus sind mit dem Rundschild mit Umbo und Speer bewaffnet, wobei die Schilde wesentlich kleiner als die des Kaisers und seiner Protectores sind. Alle Speerträger sind aufgrund ihres Helmschmucks als Cornuti anzusprechen, einzig der Helm der Figur zwischen dem Offizier und den beiden Angreifern vor der Stadt weist keine Zeichen für das Vorhandensein des Hornschmuckes auf und könnte einen anderen Truppenkörper darstellen. ${ }^{51}$ Die drei schild- und köcherlosen Sagittarii der oberen Reihe, kämpfen ebenfalls nach rechts gewandt mit Pfeil und Bogen [Abb. 8 und 9]. Die wenigen erhaltenen Fragmente der Bögen könnten nach L'Orange in Vogelköpfe auslaufen, möglicherweise jedoch zeigen sie auch bloß die typisch auslaufenden Enden eines Reflexbogens. ${ }^{52}$ Auch hinsichtlich ihrer Rüstung und Kleidung stellen die Bogenschützen den Sondertypus dar: Sie tragen keinerlei Panzerung und statt eines Helmes haben sie eine Binde um den Kopf gewunden, die gleichsam als Köcher dient, wobei die Pfeilspitze nach vorn-unten in Richtung Gesicht, der befiederte Teil nach hinten-oben hinausragt..$^{53}$ Auch kämpfen die Sagittarii nur leicht bekleidet und tragen ein lediglich lose über die linke Schulter gelegtes, chiton-ähnliches Gewand, das weite Teile der rechten Körperseite - allen voran die Schulter - freilässt. Nicht zuletzt stellt die bereits erwähnte zottig-volle Haartracht mit den spiralig aufragenden Einzellocken ein wichtiges Unterscheidungsmerkmal zum speertragenden Typus dar. Auch ihre Haltung unterstreicht die Fokussierung auf das Kampfgeschehen: Entweder sind sie im Begriff, einen Pfeil abzuschießen oder sie sind gerade dabei, ein neues Geschoss aufzulegen.

49. Otтo Seeck (Hrsg.): Notitia dignitatum, occ 5 [14], 158 = 7, 9; occ. 5 [24], 169 = 7, 18; or. 6 [9], 50. 50. L'Orange, Der spätantike Bildschmuck, 53, 62.

51. Zur Zusammensetzung des constantinischen Heereszuges siehe das anschließende Kapitel.

52. L'Orange, Der spätantike Bildschmuck, 45, 53.

53. KoEPPEL, Die historischen Reliefs, 46. 


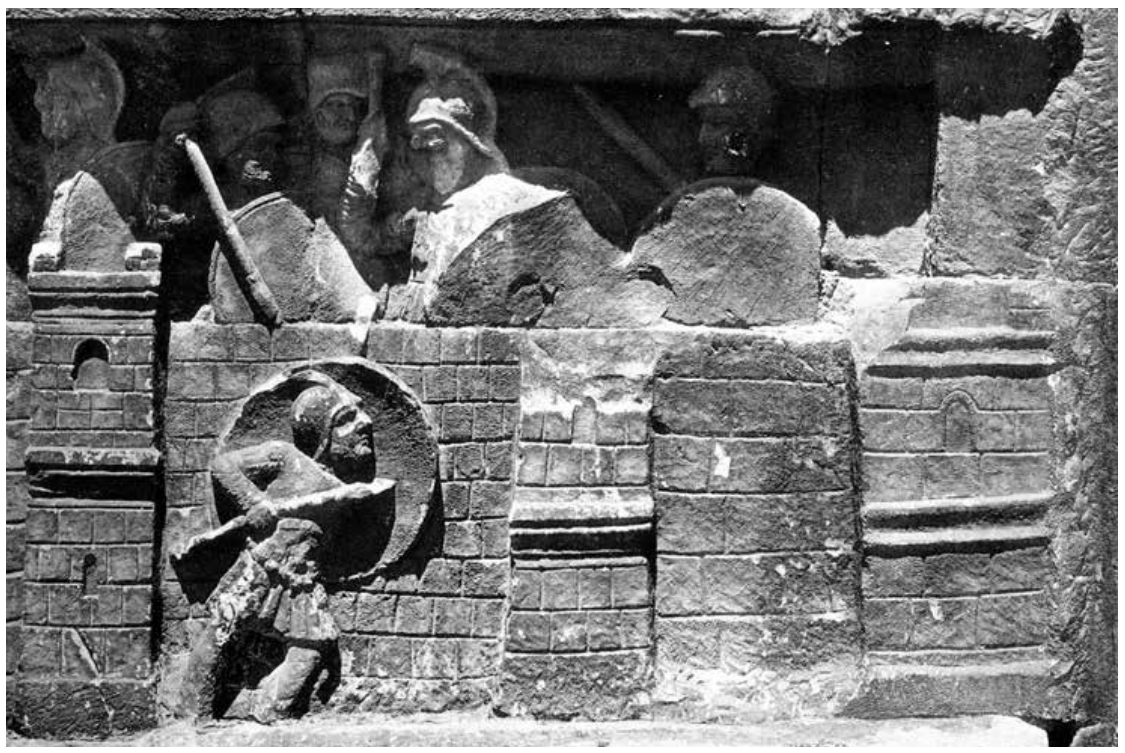

Abb. 7.: Rom, Constantinsbogen, Relief, Ausschnitt Verteidiger, Obsidio Veronae, aus: Antonio Giuliano: Arco di Constantino, 1955 Mailand, Abb. 37 r. u.

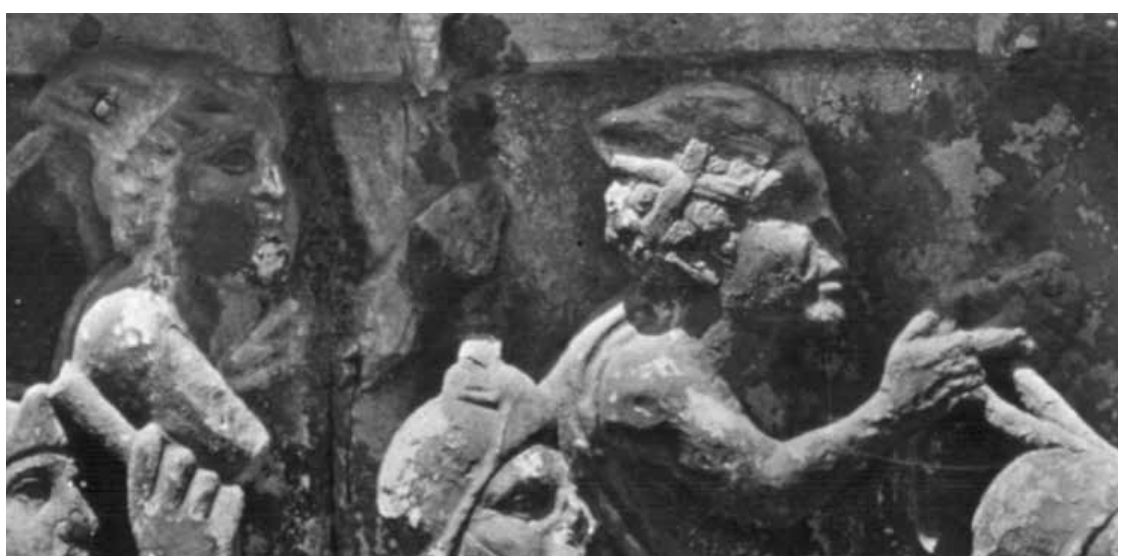

Abb. 8. Ausschnitt Sagittarii, Obsidio Veronae, aus: Antonio Giuliano: Arco di Constantino, 1955 Mailand, Abb. 38 1. o.

Die Haltung der angreifenden Truppen zeigt die Fokussierung auf das Kampfgeschehen an: Die belasteten rechten und zurückgelehnten linken Beine der Speerwerfer unterstreichen die Bewegung des rechten Armes, der zum Wurf ansetzt; die Linke hält den Schild zum Schutz des Körpers. Die Augen der Soldaten sind weit aufgerissen, die großen und runden Augäpfel haben 


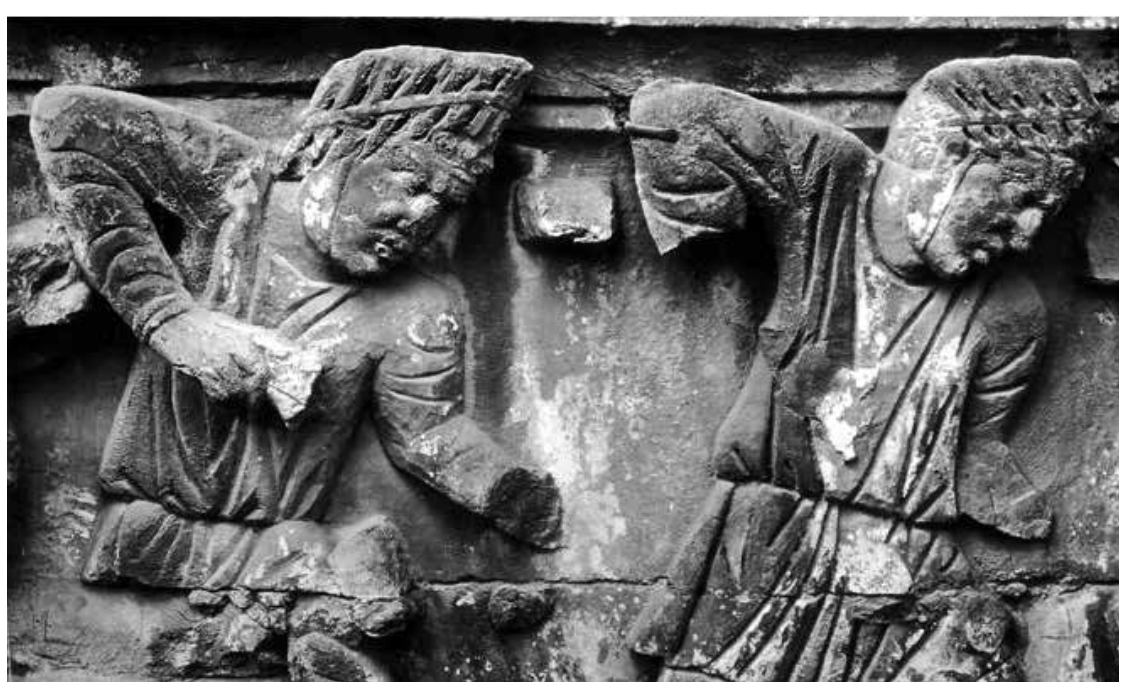

Abb. 9. Rom, Constantinsbogen, Relief, Detail Sagittarii, Proelium apud Tiberim, aus: Michael Pfanner: Vom laufenden Bohrer bis zum bohrlosen Stil. Überlegungen zur Bohrtechnik in der Antike, in: Archäologischer Anzeiger 1988, Abb. 10

die Weite des Schlachtfeldes im Blick; die Brauen folgen in ihrer Kontur dem runden Lid. ${ }^{54}$ Die Haare der im Vordergrund dargestellten Speerträger sind durch ihre Helme verdeckt; die Haartracht der Protectores reicht tief in die Stirn und wird durch parallele Linien angedeutet; das Haar des bogentragenden Sondertypus zeichnet sich durch spiralig aufragende Einzellocken aus..$^{55}$ Die allesamt bartlosen Gesichter der Soldatenfiguren sind wenig scharf gezeichnet und unterscheiden sich kaum in ihrer Individualität; ein ethnischer Unterschied zwischen Speerträgern und Bogenschützen dürfte jedoch auch in den weniger deutlich profilierten Gesichtszügen der Bogenschützen angedeutet sein. Wie die nahezu ausdruckslosen Züge der Köpfe wirken auch die Körper wenig dynamisch und ihre Bewegungen scheinen eher einer mechanistischen Ordnung zu folgen als einem dramatisch-individualistischen Bewegungsablauf; die Soldatenfiguren verschwimmen in ihrer Gesamtheit zu einem monolithischen nach rechts gewandten Bewegungsapparat. Ein nach rechts eilender Angreifer bestimmt das Geschehen vor den Mauern der belagerten Stadt und liefert die zweite Kampfdarstellung des Frieses [Abb. 7]: Abermals handelt es sich um einen Offizier der Cornuti mit Muskelpanzer, der bis auf seine gedrungene Gestalt der Rüstung, Kleidung und Bewaffnung des Offiziers rechts vor der Kaiserfigur entspricht. ${ }^{56} \mathrm{Er}$ ist der einzige Angreifer, der in der rechten Bildhälfte dargestellt wird. Der Cornutus prescht eilig in

54. L'Orange, Der spätantike Bildschmuck, 53, 60.

55. Zur Typisierung der Soldatenfiguren s. u.

56. Koeppel, Die historischen Reliefs, 46. 
Richtung des rechten Bildrandes, den Schild zum Schutz seiner Flanke gegen die Angriffe durch die Belagerten in der erhobenen linken Hand haltend, fasst er mit der rechten den Speer. ${ }^{57}$ Die große Nähe zu den Feinden und weite Entfernung zu den eigenen Truppen unterstreicht die Dynamik der Situation und liefert in gewisser Weise eine Promachie.

Den zweiten Abschnitt des Frieses, der das rechte Drittel des Reliefs ausmacht, bildet die Darstellung der in einer Stadt eingeschlossenen neun nach links bzw. nach vorn-unten gewandten Verteidiger [Abb. 2]; einer von ihnen stürzt unmittelbar hinter dem vordersten Turm kopfüber von der Stadtmauer. Die belagerte Stadt reicht vom Zentrum des hauptsächlichen Kampfgeschehens bis hin zum rechten Rand, auf den die Mauer übergreift. Die brustwehr- und zinnenlose Mauer besteht - mit Ausnahme des vordersten Mauerelementes aus regelmäßig geschichteten Quadern. Insgesamt sind fünf zweigeschossige hervorstehende Türme zu erkennen, die ebenfalls die Quaderstruktur der Mauer aufweisen. ${ }^{58}$ Die Türme verfügen über ein bis zwei Fensteröffnungen, entweder ober- oder ober- und unterhalb des Gesimses, und haben Zinnen auf der höchsten Ebene. Die in der oberen Bildebene dargestellten Verteidiger tragen die normale Kleidung, wobei nur die langärmeligen Tunicae und deren Gürtung zu erkennen sind, unterhalb des Beckens verdeckt die Mauer den Rest des Beines; alle tragen das mit einer Fibel auf der rechten Schulter geschlossenen Sagum [Abb. 7]. ${ }^{59}$ Zudem tragen die acht auf der Mauer befindlichen Verteidiger den Rundschild mit Umbo. Die Kleidung des stürzenden Verteidigers besteht aus einer langärmeligen gegürteten Tunica, der Bracae und flachen Schuhen; als einziger ist er unbewaffnet. ${ }^{60}$ Alle anderen Verteidiger tragen Helme und Rundschilde mit Mittelbuckel; sie tragen als Waffe entweder die Lanze der den Stein in der rechte Hand. Besonders die Form der Helme unterscheidet sie von den Truppen der Angreifer; es lässt sich kein einheitliches Muster erkennen: Der Helm der ersten beiden Verteidiger hat einen weit abstehenden Nackenschutz mit Wangenklappen und einen Stirnbügel. Der Helm der ersten Figur von links ist mit einem kurzen Scheitelbusch versehen, der Helm der siebten Figur von links zeichnet sich durch eine Scheitelleiste vom Stirn- bis zum Nackenschutz aus. Die Helme der übrigen Verteidiger sind mit einem langen und hohen Helmbusch geschmückt. ${ }^{61}$

Auffällig ist, dass die Verteidiger nicht in der Uniformität der angreifenden Truppen agieren [Abb. 7]. Ihre Angriffe scheinen nicht geordnet, da sie vermeintlich willkürlich mit Steinen oder Speeren zum Wurf ansetzen, während die Waffengattungen der Angreifer sich eher in zwei Reihen ordnen: Die Bogenschützen in der oberen, die speerwerfenden Cornuti in der unteren

57. Ebd.

58. Auf die bei Teilen der Mauer und der Türme fehlende Quaderstruktur als Zeichen der Unfertigkeit wurde bereits hingewiesen.

59. Koeppel, Die historischen Reliefs, 46.

60. Ebd.

61. Koeppel, Die historischen Reliefs, 46. 
Reihe. ${ }^{62}$ Auch wirken die Truppen weniger organisiert; einzig der auffallende Helmschmuck und der Mantel des zweiten Soldaten von rechts könnten möglicherweise für die Anwesenheit eines Offiziers unter den Verteidigern sprechen. Unter den Angreifern dagegen sind zwei Offiziere und die mächtige Gestalt des kaiserlichen Befehlshabers auszumachen. Die Angriffe der ersten vier Verteidiger richten sich auf die Hauptmasse der angreifenden Truppen, wobei der nach rechts eilende Cornutus die Angriffe der hinteren Verteidiger auf sich zieht; einzig der Verteidiger des rechten Randes scheint nicht in das Kampfgeschehen verwickelt zu sein. Er steht in wartender Haltung, und sein Speer ragt als einziger nicht in Richtung der Angreifer, sondern nach links oben.

Die Beschreibung des Frieses abschließend sei darauf hingewiesen, dass die bei einer Belagerung zu erwartende Belagerungstechnik auf dem Fries gänzlich fehlt. Auf dem Septimius-Severus Bogen dagegen wird bei der Darstellung der Belagerung einer Stadt ein Rammbock (Aries) dargestellt. ${ }^{63}$ Auch zur Klärung der Frage, warum dies bei der obsidio des Constantinsbogens nicht der Fall ist, wolle die folgenden Ausführungen beitragen.

\section{Zur Deutung der Kampfdarstellungen auf dem Obsidio-Fries}

Als Constantius Chlorus am 25. Juli 306 in Eboracum starb, erhoben dessen alamannische Auxilien seinen Sohn noch am selben Tag zum Augustus. Die dynastisch motivierte Usurpation Flavius Valerius Constantinus' hatte mit der ursprünglich von Diocletian installierten Nachfolgeregelung der Tetrarchie gebrochen; wieder exercitus imperatorem fecit.$^{64}$ Die Tatsache, dass der Flavier dennoch, wenn auch nur als Caesar des rechtmäßigen Augustus Severus, anerkannt wurde, stellte einen entscheidenden Präzedenzfall und einen wichtigen Faktor zur Erosion des diocletianischen Tetrarchates dar: Maxentius - der Sohn des senior Augustus Maximianus Herculius - versuchte gleiches, erfuhr jedoch keine Legitimation durch die amtierenden Kaiser. ${ }^{65}$ Kaum ein Jahr nach Diocletians Abdikation ergaben sich eine ganze Reihe handfester Auseinandersetzungen, an deren Ende ein ausgedehnter Bürgerkrieg stand allein im Jahr 310 beanspruchten sieben Augusti die Kaiserwürde. ${ }^{66}$ Als eine

62. Die einzige Ausnahme stellt der Speerträger oberhalb des Offiziers dar.

63. Zur Darstellung von Belagerungstechnik auf dem Bogen des Septimius-Severus siehe: KoEppeL, Die historischen Reliefs, 21 mit Abb. 3.

64. Epitome de Caesaribus 41, 2-3: „Constantinus, Constantii imperatoris et Helenae filius, imperavit annos triginta. Hic dum invenculus a Galerio in urbe Roma religionis specie obses teneretur, fugam arripiens atque ad frustrandos insequentes publica iumenta, quaqua iter egerat, interfecit et ad patrem in Britanniam pervenit; et forte iisdem diebus ibidem Constantium parentem fata ultima perurgebant. Quo mortuo cunctis, qui aderant, annitentibus, sed praecipue Croco, Alamannorum rege, auxilii gratia Constantium comitato imperium capit.“

65. Lact. mort. pers. 26; 44, 4. Alexander Demandt: Geschichte der Spätantike. Das römische Reich von Diocletian bis Constantin 284-556 n. Chr., München 1998, 34-35.

66. Maxentius beherrschte Rom, Alexander Africa, Maximinus Daia Syrien, Galerius Thrakien, Licinius Pannonien und Constantin und sein Schwiegervater Maximian herrschten über Gallien. 
Etappe dieses bellum civile ist der constantinische Feldzug gegen Maxentius zu sehen; Constantin strebte nach der Alleinherrschaft im Westen des Reiches. ${ }^{67}$ Im März oder April 312 überquerte Constantin mit seinen kampferprobten Verbänden aus der Gallia die Alpen beim heutigen Mont Genèvre und fiel in Oberitalien ein. ${ }^{68}$ Dabei handelte es sich um die in den germanischen Provinzen rekrutierten Truppen, ergänzt um britannische und nach dem Anschluss Hispaniens zu seinem Herrschaftsbereich 309 auch iberische Soldaten, von denen jedoch ein Großteil zur Sicherung der nach wie vor unruhigen Grenzen Britanniens und Germaniens zurückblieb. ${ }^{69}$ Dass Constantin sein Heer in den zurückliegenden Jahren verstärkt hatte, belegt der Hinweis Zosimos', dass der Augustus „Kriegsgefangene“ aus den Germanenkriegen zur Verstärkung seiner Armee heranzog. ${ }^{70}$ Insgesamt ist die Zahl von 20-25.000 Soldaten auf der Seite des Flaviers durchaus realistisch; vor allem germanische Einheiten wie die Cornuti bildeten den schlagkräftigen Kern des Heeres. ${ }^{71}$

Dass Constantin siegen würde, war keineswegs gewiss, die Städte Oberitaliens waren durch Maxentius gut befestigt worden und zahlreiche Truppen standen ihm zur Verfügung. ${ }^{72}$ Zudem waren bereits die Augusti Severus und Galerius bei dem Versuch gescheitert, Maxentius die Herrschaft

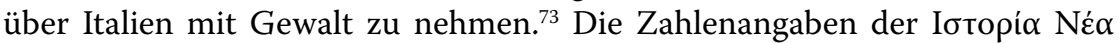
Zosimos, wonach Constantin etwa 100.000 Mann und Maxentius sogar die doppelte Menge an Truppen ins Feld führen konnten, sind, wie üblich bei antiken Quellen, überzogen ${ }^{74}$ selbst der übertreibende Panegyricus des Jahres 313 räumt Maxentius die Befehlsgewalt über nicht mehr als 100.000 Soldaten ein. ${ }^{75}$ Die Streitkräfte des Maxentius bestanden zunächst aus der Prätorianergarde, den cohortes urbanae, der Reitertruppe der equites singulares Augusti sowie möglicherweise der Legio II Parthica, insgesamt also ungefähr 23.000 Mann. ${ }^{76} \mathrm{Zu}$ addieren wären außerdem die Truppen des Severus, die nach dessen Niederlage zu Maxentius übergetreten waren, hierbei handelte es sich in etwa um 15.000 Soldaten; unter ihnen auch afrikanische Auxilia. ${ }^{77}$

67. Hartwin Brandt: Konstantin der Große. Der erste christliche Kaiser. Eine Biographie, München $2006,43$.

68. Zos. hist. 15, 1-2. Dazu: Demandt, Spätantike, 39; Отто Sснмітт: Constantin der Große. Leben und Herrschaft, Stuttgart 2007, 144

69. DemandT, Spätantike, 38.

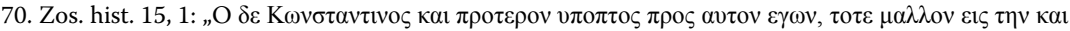

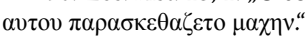

71. Sснміт , Leben und Herrschaft, 141.

72. Paneg. Lat. 12 3, 3: „Vix enim quarta parte exercitus contra centum milia armatorum histium Alpes transgressus es, [...]“; $12,5,2$ : „Tu vero etiam minoribus copiis bellum multo maius aggressus es, tanto scilicet propria tua virtute potior quanto ille numero instructior."

73. Paneg. Lat. 12 3, 4: „Duxerat magnum Severus exercitum, et hostem suum perfidia desertus armaverat; maiores postea copias Maximianus admoverat, et ipse transfugis circumcisus videbatur prospere refugisse. Ipse denique qui pater illius credebatur discissam ab umeris purpuram detrahere conatus senserat in illud dedecus sua fata transisse."

74. Zos. hist. 15, 1-2; dazu: Sснмiт T, Leben und Herrschaft, 140-141.

75. Paneg. Lat. 12, 3, 3.

76. SCHмitт, Leben und Herrschaft, 141.

77. Ebd. 
Neben der numerischen Unterlegenheit Constantins ist noch der Umstand in Betracht zu ziehen, dass die Versorgung seiner großen Armee auf italischem Boden durchaus nicht einfach zu bewerkstelligen war, dies hatte bereits der gescheiterte Italienfeldzug des Galerius offenbart. ${ }^{78}$ Trotz seiner zahlenmäßigen Überlegenheit musste der Schwiegervater des Maxentius seine Belagerung Roms auch wegen der schwierigen Versorgungslage aufgeben und unverrichteter Dinge abziehen. ${ }^{79}$ Dies bestimmte auch die Strategie Constantins: Wollte er Rom erobern, musste er schnell und aggressiv vorgehen - Maxentius dagegen konnte abwarten, seine Truppen besetzten die gut proviantierten und befestigten Städte Norditaliens und schließlich auch Rom. Dies war die militärische Ausgangslage zu Beginn der Kämpfe zwischen Constantin und Maxentius, deren Erfolg für den Flavier die Friese des Constantinsbogens dokumentieren.

Die Tatsache, dass auf dem Bogen nur zweiunmittelbare Kampfdarstellungen zu finden sind, lassen vermuten, dass es sich dabei um die zwei zentralen Episoden aus Constantins Italien-Feldzug handeln dürfte. Die Schlacht an der Milvischen Brücke auf dem Bogen darzustellen, ergab sich aus ihrem Entscheidungscharakter, sie bot den eigentlichen Anlass zu Errichtung des Ehrenmonumentes. ${ }^{80}$ Darüber hinaus ist anzunehmen, dass es sich bei der zweiten Darstellung, der Belagerung einer Stadt, um den Kampf vor den Mauern Veronas handeln dürfte, denn der Sieg in Verona stellte eine strategisch wichtige Etappe dar. Tatsächlich war die Belagerung Veronas nicht das erste Aufeinandertreffen der Kontrahenten: Bereits in Segusio (Susa) und Augusta Taurinorum (Turin) hatte Constantin sich gegen seinen Kontrahenten durchsetzen können und kurze Zeit später Mailand dem Sieger bereitwillig seine Tore geöffnet. Damit war die erste Etappe des constantinischen Feldzuges abgeschlossen; Constantin hatte sich in Oberitalien erfolgreich etabliert. ${ }^{81}$ Aber erst nach der erfolgreichen Einnahme Veronas war der Weg nach Rom frei. ${ }^{82}$ Die Stadt an der Etsch (Athesis) war von Maxentius mit einer großen Garnison belegt worden, befehligt von dem fähigen praefectus praetorio Ruricius Pompeianus. ${ }^{83}$ Ein feindlich besetztes Verona hätte jedoch für die Flanken des constantinischen Heereszuges bei einem Vorstoß Richtung Süden

\footnotetext{
78. SCHMitT, Leben und Herrschaft, 144.

79. RichaRd KLEIN: «Galerius. 305-311», in: Manfred Clauss (Hrsg.): Die römischen Kaiser. 55 Potraits von Caesar bis Iustinian, München 2005, 276-282, hier 279.

80. Siehe dazu weiter oben.

81. Sснміт , Leben und Herrschaft, 146.

82. Paneg. Lat. 12, 5, 4-6: „Probavit hoc prima obstinatio eorum qui, sub ipsis Alpium iugis munitissimum licet muro ac situ tenentes oppidum, ausi fuerunt te imminente resistere ac portas claudere; non credentes illi quidem, ut audio, ipsum te adesse [...]; Luerunt igigutr ilico dementiae suae poenas, cum oblatam sibi a clementia tua veniam recusassent. Neque enim vallo fossaque obsessio inchoata est, nec cuiniculis agendis nec machinis admovenis nec incutiendo ariete temptati quassatique sunt muri, sed statim iniectae faces portis, scalae propugnaculis, nec solum fundis eminus telisque missilibus sed hastis gladiis. Ita res simul coepta et patrata, iunctusque rebellibus fuit conaatus et exitus." Für die Beschreibung der offenen Feldschlacht um Augusta Taurinorum siehe: Paneg. Lat. 12 6, 2-5. Dazu: Demandt, Spätantike, 39.

83. BRAndt, Konstantin der Große, 43.
} 
eine erhebliche Bedrohung dargestellt; von der wichtigen Versorgungsfrage und dem drohenden Abriss der Verbindungen in die Gallia ganz abgesehen. Constantin musste Verona erobern, wollte er nach Rom ziehen. Im August des Jahres 312 kam es nach einigen Vorgeplänkeln zur Schlacht um Verona, deren Verlauf uns der Panegyricus aus dem Jahr 313 wie folgt schildert:

„Doch es wurde ja jenes leidgeprüfte Verona, das schon vor langer Zeit besudelt worden war vom Blut des Bürgerkriegs, vom größten Heer der Feinde besetzt gehalten, den entschlossensten Führern und einem höchst hartnäckigen Präfekten, offensichtlich, damit die Städte, die Cn. Pompeius einst als Kolonie gegründet hatte, Pompeianus der Vernichtung preisgeben konnte.[...] Denn jene Etsch, starrend vor Felsen, an Strudeln und an Wirbeln reich und wild in ungestümem Lauf, machte einen Sturmangriff unmöglich und verlieh dem ganzen Land dahinter gegen das Vordringen von Truppen Sicherheit und Schutz. Dass dies dem Feind trotzdem längerfristig keinen Nutzen brachte, ist deiner Vorausplanung zu verdanken: denn an weiter oberhalb gelegenen Stellen, wo die Strömung des Flusses sanfter war und die Feinde keinerlei Argwohn hegten, hast du einen Teil des Heeres übersetzen lassen und in verdoppelter Gefahr die von der Blockade ringsum Eingeschlossenen gezwungen, die Hoffnung auf einen Aufschub preiszugeben und ihr Glück im Kampf zu erproben; und alle, die den Versuch eines Ausbruchs unternommen hatten, hast du in solch ein Gemetzel verstrickt, dass der Führer selbst [Rauricius Pompeianus, d.A.] mit einem Teil seiner Truppen die Stadt verlassen hat, um Hilfstruppen herbeizuschaffen [...] um mit größerer Begleitmannschaft in seiner Niederlage unterzugehen. Gerade in dieser Situation wurden, Imperator, deine Sorge und zugleich die Größe deines Mutes besonders deutlich sichtbar, da du gegen jene bei seiner Rückkehr lieber mit einem kleineren Heer kämpfen als die Belagerung unterbrechen wolltest, um nicht den Eingeschlossenen Gelegenheit zu bieten, Atem zu schöpfen oder die Flucht zu ergreifen oder deine Soldaten im Rücken $\mathrm{zu}$ bedrohen. Und zunächst hattest du ja, wie ich höre, die Schlachtreihe in doppelter Linie aufgestellt; bald darauf, als du die Zahl der Feinde vor dir sahest, hast du den Befehl erteilt, die Reihen sollten sogleich in Frontstellung auseinandertreten und die Waffenmacht in breiterer Linie ausgedehnt werden - dabei hast du natürlich den Mut all deiner Leute nach deinem eigenen bemessen und warst überzeugt, eine noch so überlegene Masse könne dann durch den Ansturm auch einer relativ geringen Zahl zerschlagen werden. ${ }^{\text {"84 }}$

Mit den Worten constantinischer Propaganda berichtet der unbekannte Panegyriker von der Ausgangssituation, wonach Verona von einer starken Garnison der Truppen des Maxentius - geführt von dem Prätorianerpräfekten Pompeianus - gehalten wurde. ${ }^{85}$ Für den constantinischen Feldzug gegen Maxentius kam Verona nicht nur eine strategisch äußerst hohe Bedeutsamkeit

84. Paneg. Lat. 12 8, 1 - 9, 1, (Übers. Müller-Rettig).

85. Zum Panegyricus des Jahres 313 siehe: Brigitte Müller-Rettig: Panegyrici Latini. Lobreden auf römische Kaiser. Bd. I. Von Diokletian bis Constantin, (=Müller-Rettig Übers. u. Komm.), Darmstadt 2008, 267-275. 
zu, lag sie doch an wichtigen Nord-Süd- und Ost-West-Verbindungen, namentlich der Via Gallica, der Via Claudia Augusta und der Via Postumia. ${ }^{86}$ Auch der Umstand, dass sich die wichtigen Städte Auquileia und Mutina (Modena) nach dem Sieg in Verona samt ihren Garnisonen Constantin unterwarfen, war rückblickend von enormer Wichtigkeit für den erfolgreichen Vormarsch auf Rom. ${ }^{87}$

Wie oben bereits ausgeführt, zeigt der Fries zwei Kampfdarstellungen: Den Ansturm der Hauptarmee auf die Stadt, sowie den schnellen Vorstoß eines Vorab-Detachements - auf dem Fries durch den nach rechts eilenden Cornutus dargestellt - über die Etsch und das damit verbundene taktisch wichtige Schließen des Belagerungsringes ${ }^{88}$ Darin fügen sich die Aussagen des Panegyrikers, der von der Unmöglichkeit berichtet, die durch den Fluss gedeckte Stadt im Sturm zu nehmen, weshalb sich Constantin entschieden habe, den Belagerungsring um die Stadt auch über die Etsch hinweg zu schließen, um Verona von Nachschub und Verstärkungen abzuschneiden. Dies Vorgehen erwies sich jedoch als sehr schwierig, denn bis weit nach Norden mussten die Umfassungstruppen vorstoßen, ehe sie die Stadt über die Etsch hinweg auch von Norden und Osten abriegeln konnten. ${ }^{89}$ Zudem spricht die Quelle auch von der Schlachtreihe in doppelter Linie, die sich ebenfalls sehr deutlich auf dem Fries wiederfinden lässt. Die Tatsache, dass die Haupt-Kampflinie des Frieses bis auf wenige Schritte vor die Mauern Veronas getragen wurde, sowie der Umstand, dass die Cornuti gerade zum Wurf ihrer Speere auf die Verteidiger ansetzen, belegt, dass es sich um einen direkten Angriff auf Verona handelte. Darin fügt sich auch der Umstand, dass die Verteidiger ebenfalls ihre Fernkampfwaffen einsetzen. Sogar mit Steinen versuchen sie, die Angreifer abzuwehren, die Entfernung zu den Feinden scheint denkbar gering, handelt es sich bei dieser Art des Einsatzes um keine Waffen für eine größere Distanz..$^{90}$ Einer der Verteidiger stürzt vermeintlich getroffen von der Mauer herab, auch dies belegt, dass es sich um einen zentralen Moment der Schlacht handelt.

86. Sснміт , Leben und Herrschaft, 138-140.

87. Paneg. Lat. 12 11, 1. - Die Kirchengeschichte des Eusebius stellt den constantinischen Feldzug wie folgt dar: Eus. hist. eccl. 9: „Konstantin, der Oberste im Reiche an Würde und Rang, hatte Mitleid mit den bedrückten Einwohnern Roms. Nachdem er Gott, der im Himmel ist, und sein Wort, den Erlöser aller, Jesus Christus, im Gebete zu Hilfe gerufen, rückte er mit der ganzen Streitmacht vor, um den Römern die von den Ahnen ererbte Freiheit wiederzugeben, Maxentius, der mehr auf Zauberkünste als auf die treue Gesinnung seiner Untertanen baute, wagte es nicht, auch nur den Fuß vor die Tore der Hauptstadt zu setzen. Auf jeden Platz und in jeden Flecken und jede Stadt, die im Umkreis von Rom und in ganz Italien von ihm unterjocht waren, hatte er eine ungezählte Menge von Schwerbewaffneten und unendliche Abteilungen von Legionären gelegt. Im Vertrauen auf den göttlichen Beistand griff der Kaiser [Konstantin, d. A.] die erste, zweite und dritte Stellung des Tyrannen an, die er alle spielend nahm, marschierte weiter im Inneren Italiens vor und kam bis in die Nähe Roms. Um Konstantin den Kampf mit den Römern, der ihm des Tyrannen wegen bevorstand, zu ersparen, zog Gott selber den Tyrannen wie an Ketten weit aus den Toren der Stadt heraus." Zitiert nach: EusEBIUs. Ausgewählte Schriften Band II: Kirchengeschichte, (= Übers. Philip Häuser), Bibliothek der Kirchenväter, 2. Reihe, Band 1, München 1932, 422-423.

88. Der Mauerring Veronas erstreckte sich über beide Ufer der Etsch. Dazu: L'OrangE, Der spätantike Bildschmuck, 65 mit Anm. 2.

89. Schmit T, Leben und Herrschaft, 147.

90. Anders verhielte es sich mit Schleuderern, die jedoch auf dem Fries nicht dargestellt werden. 
Auch die auf dem Fries dargestellten Truppen sind mit Hilfe des Panegyricus historisch kontextualisierbar: Für die Besonderheit der in der oberen Reihe dargestellten Bogenschützen liefert uns der Panegyricus folgende Erklärung: Es handelt sich um maurische Auxilia, die im Vorfeld der Schlacht um Verona zu Constantin gewechselt hatten. ${ }^{91}$ Diese afrikanischen Truppen waren einst mit Severus, der auch Herr über die Diözese Africa war, im Jahr 307 gegen Maxentius gezogen, doch waren sie anschließend zu Maxentius übergelaufen; nun hatten sie sich Constantin angeschlossen. ${ }^{92}$ Vor dem Hintergrund des provinzialrömischen Charakters des constantinischen Heeres wird auch die Herkunft der Cornuti erklärt: Der besondere Helmschmuck dieser Einheiten belegt ihre gallische Herkunft; Constantins Truppen rekrutierten sich aus germanischen, gallischen und britannischen Stämmen..$^{93}$ Ihre herausgehobene Bedeutung auf dem Obsidio-Fries wird durch ihre Positionierung an den entscheidenden Stellen des Kampfgeschehens erreicht. Diese Situation bildet den Kern der Darstellung der Belagerung Veronas auf dem Constantinsbogen.

An dieser Stelle jedoch geht die schriftliche Quelle noch über die Aussagen des Frieses hinaus: Sie unterstreicht den Erfolg der constantinischen Taktik, „hat die Belagerung durch [Constantin, d. A.] sie doch weniger in Bedrängnis gebracht als der interne Druck seitens der Spießgesellen! "94 Der geschlossene Belagerungsring um Verona bedingte, dass die Garnison einen Ausfall machen musste, um nicht aus Mangel an Versorgung und Nachschub die Hoheit über die Stadt zu verlieren; dabei sei es zu schweren Kämpfen gekommen. ${ }^{95}$ Anscheinend gelang es Pompeianus mit einem massierten Ausfall den Belagerungsring $\mathrm{zu}$ durchbrechen und Entsatztruppen heranzuführen, während die constantinischen Truppen Verona weiterhin belagerten. ${ }^{96}$ Die von Pompeianus herangeführte Verstärkung konnten durch die constantinischen Truppen abgewehrt werden und der Prätorianerpräfekt Pompeianus verlor Schlacht und Leben; Verona ergab sich dem siegreichen Constantin. ${ }^{97}$ Zudem öffneten Auquileia und Mutina (Modena) dem Flavier ihre Tore, damit war

91. Der Panegyriker berichtet uns in Paneg. Lat. 12 7, 1-4 vom Übertritt vieler wichtiger Städte zu Constantin: „Quid tibi aliud sperare potuisti, miles infelix, turpissimo illi tunc devote prodigio? Iam enim non insulto sed doleo. Constantium tu tantum snguinis fundere coegisti, cui, quia salutem vestram a vobis impetrare non licuit, paene displicuit ipsa victoria. At non Taurinatibus neque ceteris Italiae civitatibus idem animus fuit, qui te, imperator, exsultantes gaudio certatim ad se vocaverunt. Missae ab omnibus legationes, oblati undique commeatus, ut appareret quam diu desiderassent cui se tam prompte bello adhuc restante committerent." Aller Wahrscheinlichkeit nach erfolgte der Übertritt der maurischen Auxilia nach der Übergabe Augusta Taurinorums oder Mediolanums an Constantin.

92. Paneg. Lat. 12 7, 1. Dazu: L’Orange, Der spätantike Bildschmuck, 50

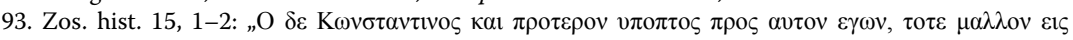

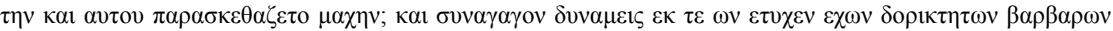

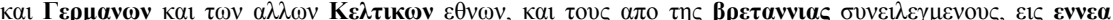

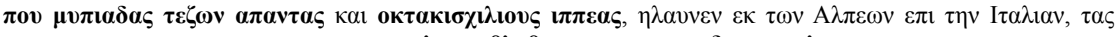

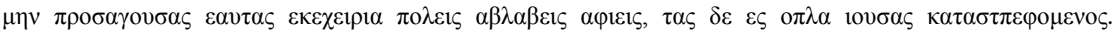
[Hervorhebung d. A.]“

94. Paneg. Lat. 12 8, 2, (Übers. Müller-Rettig).

95. Sснміт, Leben und Herrschaft, 148.

96. Ebd.

97. Ebd. 
ganz Italien nördlich des Po in seiner Hand. ${ }^{98}$ Doch bei genauerer Betrachtung ergibt sich ein bemerkenswerter Unterschied zwischen Bild- und Textquelle, der für die vorliegende Untersuchung von höchstem Interesse ist, und zwar bei der Frage, wie sich die schriftlichen Belege zu der Darstellung der Kaiserfigur auf dem Obsidio-Fries verhalten: Von einem dem Kampfgeschehen entrücktem Kaiser jedenfalls weiß der Panegyricus nichts zu berichten:

„Bald darauf [nach dem Eintreffen der Verstärkungen für Pompeianus, d.A.], als du die Zahl der Feinde vor dir sahest, hast du den Befehl erteilt, die Reihen sollten sogleich in Frontstellung auseinander treten und die Waffenmacht in breiterer Linie ausgedehnt werden [...] Du hattest alle Dinge im Voraus bedacht, die Gesamteinteilung vorgenommen, die Aufgaben des obersten Befehlshabers erfüllt: Warum hast du selbst gekämpft? Warum dich unter die dichtesten Haufen der Feinde gemischt? Warum das Wohl des Staates in so große Gefahren gebracht? Oder glaubst du, wir wüssten nicht, dass du, als dich allzu feurige Leidenschaft dahinriss, mitten unter die Waffen der Feinde geraten bist, und wenn du dir nicht durch Mord und Gemetzel einen Weg eröffnet hättest, Hoffnung und Wünsche des gesamten Menschengeschlechtes betrogen hättest? ${ }^{499}$

Constantin griff pesönlich in die Schlacht ein und Pompeianus tat auf seiner Seite das gleiche. ${ }^{100} \mathrm{Im}$ Bericht des Panegyrikers ist dies der dramatische Höhepunkt des Kampfes um Verona, wenn der Kaiser selbst an vorderster Front gegen seine Feinde kämpft, während die Kaiserfigur des Obidio-Frieses weder in der ersten Reihe zu finden ist, noch sein Schwert fasst, geschweige denn Feindberührung hat. Einen deutlichen Beleg für den chronologischen Unterschied zwischen der auf dem Fries und der schriftlich Fixierten Szenerie des Kampfes um Verona kann beispielsweise anhand der Truppenformation nachvollzogen werden. Sind die Angreifer der Obsidio noch in der besagten Doppelreihe gestaffelt, schreib der Lobredner von der Auflösung dieser Formation zugunsten einer breit aufgestellten Front in Erwartung des Gegenangriffes der verstärkten Truppen des Pompeianus bzw. des Maxentius. Dabei können wir davon ausgehen, dass der Bericht des Panegyricus von 313 zumindest den groben Verlauf der Schlacht recht wahrheitsgetreu wiedergibt. ${ }^{101}$ Beide Darstellungen unterscheiden sich demnach in ihrer Darstellungsabsicht: Der Obsidio-Fries stellt nicht den kämpferischen Höhepunkt des historischen Geschehens - den unmittelbaren Sieg über die ausfallenden Truppen des Maxentius - dar, sondern demonstriert die militärisch-taktische Überlegenheit

98. Paneg. Lat. 128,3

99. Paneg. Lat. 12, 9, 1; 3-5 (Übers. Müller-Rettig).

100. Paneg. Lat. $12,8,3$

101. Immerhin hält der unbekannte Lobredner seinen Vortrag vor Constantin und dessen Trierer Hof, was eine allzu phantasievolle Erzählung der Schlacht unwahrscheinlich werden lässt, dazu: BRIGITTE Müller-Rettig: Panegyrici Latini. Lobreden auf römische Kaiser. Bd. I. Von Diokletian bis Constantin, (=Müller-Rettig Übers. u. Komm.), Darmstadt 2008, 267-275. 
Constantins: Wie oben beschrieben erscheint seine große Gestalt mit der erhobenen, geöffneten rechten Hand im Gestus der Sonnenkaiser als alles lenkende Figur, die das Kampfgeschehen ultimativ steuert. Sol Invictus geriet dabei zum „besonders sprechendem Symbol der kaiserlichen Kosmokratie“ (L'Orange), von der auch das Schlachtfeld keine Ausnahme machte. ${ }^{102}$ Es war Constantins Entschlossenheit, den Belagerungsring gänzlich zu schließen, auch auf die Gefahr hin, dass die ausgedünnten Linien einem massierten Ausfall nicht würden standhalten können, die die Schlacht um Verona entschied. ${ }^{103}$ Dies belegt die herannahende Victoria, die in der römischen Triumphalikonographie nicht für die Fähigkeit des Siegens, sondern für den Sieg selbst steht: Sie schwebt mit Lorbeer und Tropaion auf die Kaiserfigur zu und liefert den deutlichen Beleg für das unmittelbare Bevorstehen des Sieges qua überlegener Taktik. ${ }^{104}$ Doch obgleich auch der Panegyricus den Kaiser als Schlachtenlenker für dessen Taktik und Befehle lobt (summi imperatoris officia compleveras), betont er vor allem die kaiserliche virtus militis als Kämpfender, wenn er anders als Xerxes bei Salamis oder Augustus bei Actium selbst in den Kampf eingriff. ${ }^{105}$ Doch warum variiert die Darstellungsabsicht beider Quellen und welche Intentionen könnten ausschlaggebend gewesen sein, nicht den tatsächlichen Höhepunkt der Schlacht um Verona, das Aufeinandertreffen beider Heere im Felde, sondern die erfolgreiche feldherrliche Befehlsgewalt auf dem constantinischen Fries als Grund für den Sieg anzugeben? Eingedenk der Tatsache, dass der Panegyricus von 313 in Trier gehalten wurde, ließe sich die Vermutung anstellen, das die drastische Schilderung des Eingreifens des Kaisers und des blutigen Gemetzel unter den besiegten römischen Soldaten dergestalt nur nördlich der Alpen vermittelt werden konnte. Doch wie der Redner in Trier 313, so berichtet auch Nazarius im Jahr 321 von dem persönlichen Eingreifen des Kaisers und dessen Tötung römischer Soldaten. Dies tat er vor dem römischen Senat, dem die Ereignisse noch bestens bekannt gewesen sein dürften. ${ }^{106}$ Die ideologische Umdeutung der victoria civilis war also ein reichsweites Phänomen, das sich auch vor

102. Zitiert nach: KuRT ALAND: «Das Verhältnis von Kirche und Staat in der Frühzeit», in: Wolfgang Haase (Hrsg.): Aufstieg und Niedergang der römischen Welt II, 23, Bd. 1, Berlin 1979, 60-246, hier 126.

103. Paneg. Lat. 12 8, 3: „Quod tamen ne diutis hostem iuvaret providentia tua factum est, cum superioribus in locis, qua lenior amnis et ignari hostes erat, exercitus parte proiecta, ancipiti priculo clausos obsessosque omissa spe morae experiri armis coegisti [...]." [ Hervorhebung d. A.]

104. Dietrich Wachsmuth: «Victoria», in: Der Kleine Pauly Bd. V, Sp. 1262-1264.

105. Paneg. Lat. 9, 3, 10, 1: „Spectavit ex edito monte Xerses navale certamen; Augustus aliud agens vicit apud Actium."

106. Paneg. Lat. 4, 26: „O nox illa aeternis saeculis monumentumtisque mandanda! cum spissis tenebris [de] congressu Fortunate totum liceret; tu tamen, imperator, non intutior tempore quam deo tectior, saevissimo hosti multus instares et libertate caedis exultans donum noctis duceres quod pugnantem nemo servaret. Nihil enim te permovent tubarum fractae voces, horrendus militium clamor, permissa casibus vulnera, inlisi cominus gladii, cadentum graves gemitus, arma late strepentia et in unum quendam sonitum diversi fragoris acta confusio, quod haec omnia aut virtus neglegit aut ira non sentit. [...] Proelio vix multa nocte confecto fessus caedibus, anhelus ex bello, cruore oblitus sed hostili, ad obsidonis vigilas recurrebas." [Hervorhebung d. A.] Zitiert nach: Charles Nixon, Barbara Rodgers (Hrsg.): In Praise of later Roman Emperors. The Panegyrici Latini, Oxford 1994, 620. 
der römischen Senatsaristokratie vermitteln ließ.107 Dies verstärkt die Frage, inwiefern dieser Wandel Einfluss auf die Bildgestaltung der constantinischen Friese gehabt haben könnte. Bevor eine abschließende Antwort auf diese und andere Fragen geliefert werden kann, soll ein Exkurs auf die Darstellung der Kaiserfigur des zweiten Schlachtenfrieses am Constantinsbogen erfolgen. Die dabei gewonnenen Einsichten sollen als Korrektiv der Bewertung der Kaiserdarstellung der Obsidio dienen.

\section{Der Fries „Proelium apud Tiberim“}

Wie die Obsidio findet sich die Darstellung der Schlacht bei pons Milvius auf der Südseite des Bogens, doch oberhalb des rechten Seitendurchganges [Abb. 10 und 11]. Die Gesamtlänge des Frieses beträgt 5,47 m mit den Seitenrändern, die Höhe des figurierten Teils misst zwischen 0,88 und 0,94 m. ${ }^{108}$ Der Fries besteht aus zwei Blockreihen, die übereinander gelagert sind, wobei der obere Abschluss des rechten Blockes weggebrochen ist; die maximale Relieftiefe beträgt $0,10 \mathrm{~m} .{ }^{109}$ Wie bei dem Obsidio-Fries zeichnet sich der Reliefgrund durch eine wellenartige Beschaffenheit aus und wölbt sich oben und an beiden Seiten etwas hervor. Das Relief läuft nach oben gegen einen sich zwischen zwei Leisten befindlichen Karnies aus; teilweise ragt die Figuration bis in den oberen Rand hinein. ${ }^{110}$ Nach links und rechts wird das Relief von zwei Leisten begrenzt, nach unten durch das hervorragende Gesims der anschließenden Quaderschicht. ${ }^{111}$ Der Fries ist stark beschädigt worden, allem voran die Figur des Kaisers, wofür Metalldiebe verantwortlich zeichnen, indem sie bis auf die Dübel der Quaderwand vorstießen. Wie bei der Obsidio wechseln sich Bohrer und Meißel als Gestaltungsmerkmal des Frieses ab. ${ }^{112}$

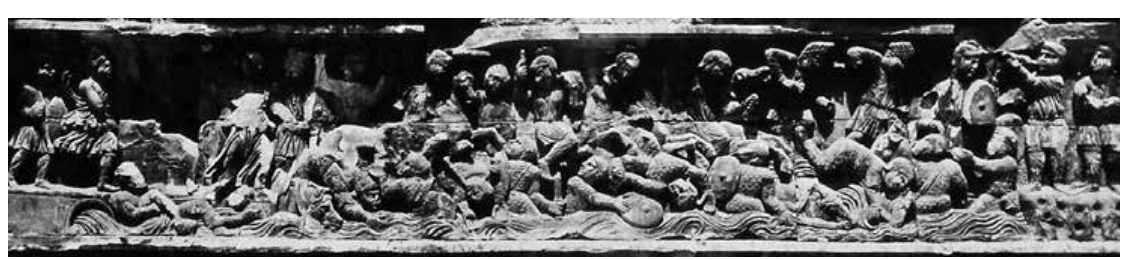

Abb. 10: Rom, Constantinsbogen, Schlachtenfries oberhalb des rechten Seitendurchganges an der südlichen Schmalseite, Proelium apud Tiberim, aus: EMANuEL MAYER: Rom ist dort, wo der Kaiser ist. Untersuchungen zu den Staatsdenkmälern des dezentralisierten Reiches von Diocletian bis zu Theodosius II., Mainz 2002. Taf. 38-3

107. Johannes Wienand: «Der Kaiser als Sieger. Metamorphosen triumphaler Herrschaft unter Constantin I.», in: Klio, Beihefte NF 19, Berlin 2012, 281-287.

108. Koeppel, Die historischen Reliefs, 47.

109. Ebd.

110. Ebd.

111. L'Orange, Der spätantike Bildschmuck, 65.

112. Ebd. 


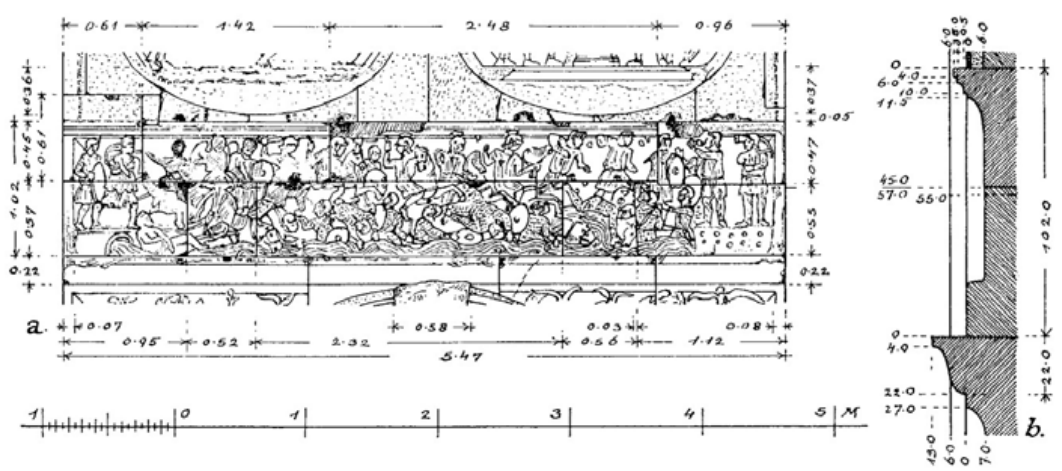

Abb.11: Rom, Constantinsbogen, Umzeichnung und Abmessungen, Proelium apud Tiberim aus: Hans Peter L'Orange; Armin von Gerkan: Der spätantike Bildschmuck des Konstantinsbogens, Studien zur Spätantiken Kunstgeschichte 10, Berlin 1939, Abb. 11

Anders als die Obsidio stellt das Proelium eine offene Feldschlacht dar. ${ }^{113}$ Den größten Teil der unteren Reliefebene nimmt die Darstellung der Wellen eines Flusses ein, der sich durch einen Brückenbogen am linken Rand kommend bis zu einem Ufer am rechten Rand erstreckt, das wohl das Rom zugewandte Tiberufer zeigt. ${ }^{114}$ Das breite Zentrum der Komposition stellt eine Schlacht am Ufer dieses Flusses dar; flankiert wird das Geschehen durch zwei Hornbläser - tubicen und cornicen auf einem Felsen - auf der rechten und die Kaiser-Götter-Gruppe auf der linken Seite stehend [Abb. 10]. ${ }^{115}$ Rechts an das Fragment der abgebrochenen Brücke anschließend ist ein Schiff dargestellt, rechts davor ragt ein Pfeiler aus dem Wasser. ${ }^{116}$ War die Isolierung der Kaiserfigur der Obsidio schon klar ersichtlich, so wird sie nirgends deutlicher zum Ausdruck gebracht, als bei der Darstellung der Schlacht an der Milvischen Brücke: Die heute fast gänzlich fehlende Figur des Kaisers wird von einer Götter-Gruppe vom restlichen Kampfgeschehen nahezu abgeschirmt und befindet sich noch dazu als einzige Figur des Frieses auf dem an das Brückenfragment anschließende Schiff [Abb. 12]. Die personifizierte Roma nähert sich dem Kaiser von links auf den Resten der Brücke, unter diesem schaut vor dem Schiffsrumpf die Flussgottheit Tiber zum Kaiser auf. Links daneben, auf dem Pfeiler stehend, bekränzt die Victoria den Kaiser. Schon die Stellung der Figur an solch einer prominenten Stelle inmitten der Götter zeigt ihren kaiserlichen Rang an, wobei heute nur noch Teile der Füße, der Sandalen, des an der Hüfte getragenen Schwertes und der Saum des Paludamentums zu erkennen sind.

113. In Anbetracht des begrenzten Raumes sollen die Ausführungen das Proelium betreffend lediglich dazu dienen, die zuvor gewonnen Einsichten zu vergleichen; für eine ausführliche Besprechung sei auf die entsprechende Literatur bei L'ORANGE und KOEPPEL verwiesen.

114. Koeppel, Die historischen Reliefs, 47.

115. L'OrAnge, Der spätantike Bildschmuck, 66-67

116. Ebd. 


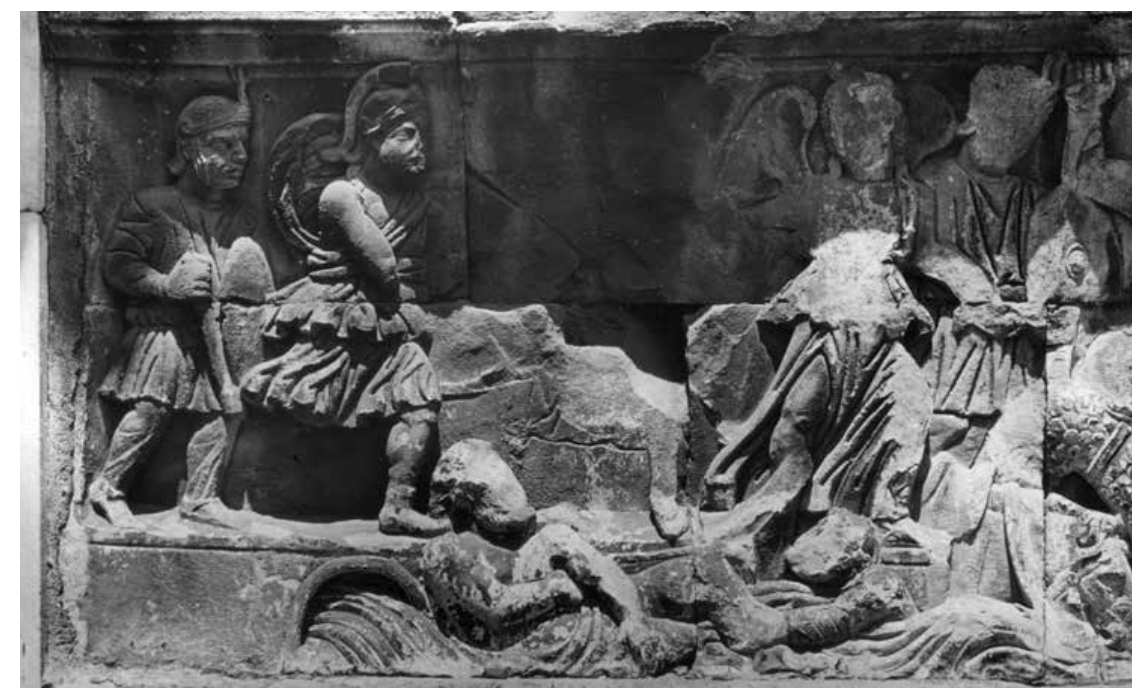

Abb.12. Rom, Constantinsbogen, Relief, Ausschnitt Kaiser-Götter-Gruppe, Proelium apud Tiberim, aus: Antonio Giuliano: Arco di Constantino, Mailand 1955, Abb. 38 l. o.

Die Haltung der Kaiserfigur entspricht ganz der des Obsidio-Frieses: Ihre Füße zeigen eine gelassene Haltung an, beide sind vorwärts gerichtet, wobei der linke Fuß etwas stärker belastet ist; dazu passt, dass er das Schwert nicht in der Hand hält. Wie bei der Belagerung wird auch der Kaiser der Tiberschlacht in Frontalansicht dargestellt, der Reliefgrund lässt erkennen, dass sein Kopf nach vorn dem Schlachtgeschehen zugewandt war; Kleidung und Rüstung werden ebenfalls dem Obsidio-Kaiser entsprochen haben. ${ }^{117}$ Zudem ist auf dem Reliefgrund eine Auskerbung zu erkennen, die auf einen gesondert gefertigten Kaiserkopf schließen lässt. ${ }^{118}$ Hervorzuheben ist der Umstand, dass die körperliche Größe der Kaiserfigur den Soldaten des Frieses - verglichen etwa mit dem Speerträger am rechten Bildrand - entspricht; ganz anders als bei dem Obsidio-Fries. Ob die Hand der Kaiserfigur erhoben war, darüber lassen sich heute keine Aussagen mehr treffen.

Die drei den Kaiser umgebenden Götterfiguren sind die Dea Roma, die Flussgottheit Tiber und eine Victoria [Abb. 12]. ${ }^{119}$ Die amazonenhafte Roma ist mit einem Chiton bekleidet, der die rechte Schulter und Brust freilässt, darüber trägt sie einen um die Taille gewundenen Mantel, hohe Stiefel, einen Helm mit Nackenschutz und Stirnschirm und außerdem hält sie einen Speer von dem heute nur ein Rest vor dem Helm zeugt - sowie einen Rundschild. ${ }^{120}$

117. Ebd.

118. Koeppel, Die historischen Reliefs, 48

119. Ebd.

120. L'Orange, Der spätantike Bildschmuck, 67. 
Der Flussgott Tiber liegt mit übereinandergeschlagenen Beinen vor dem Rumpf des Schiffes im Wasser; seine rechte Hand verbirgt er unter dem linken Arm und sein Unterkörper ist in einen Hüftmantel gehüllt. ${ }^{121}$ Die rechts vor dem Kaiser befindliche Victoria trägt einen Chiton mit Kolpos und Sandalen an den Füßen; ihr schulterlanges Haar ist über der Stirn gebunden. In der rechten Hand fasst sie den Lorbeer um den Kaiser zu bekränzen, mit der linken hält sie die Palme. ${ }^{122}$ Ihre Körperhaltung und die Stellung ihrer Beine zeigen an, dass die Victoria nach rechts eilt, um den Kaiser mitzureißen.

Rechts neben der Kaiser-Götter-Gruppe entspinnt sich das verschlungene Kampfgeschehen in den Fluten des Flusses, dargestellt in aneinandergereihten Einzelkämpfen[Abb.13und14]. Dabeiisteswichtig, dass dieBewegungsrichtung sich nicht wie üblich von rechts nach links erstreckt, sondern dass die Soldatenfiguren der oberen Ebene auf dem Ufer des Tibers stehen und die Besiegten in das Wasser drängen; die Kampfdarstellung entwickelt sich also aus der Tiefe des Reliefs in den räumlichen Vordergrund. Das Geschehen findet dabei am Tiberufer hinter der dargestellten zerstörten Brücke statt und zeigt den Kampf der Angreifer von oben-hinten nach unten-vorn in Richtung des Flusses. Diese besondere räumliche Ausdehnung des Kampfgeschehens bricht mit der blockartigen Ordnung der Obsidio, ermöglicht jedoch gleichzeitig eine gefächerte Darstellung des Geschehens. Einzig die doppelreihige Anordnung der Kämpfenden stellt eine Parallele zum Belagerungs-Relief dar; auch ergibt

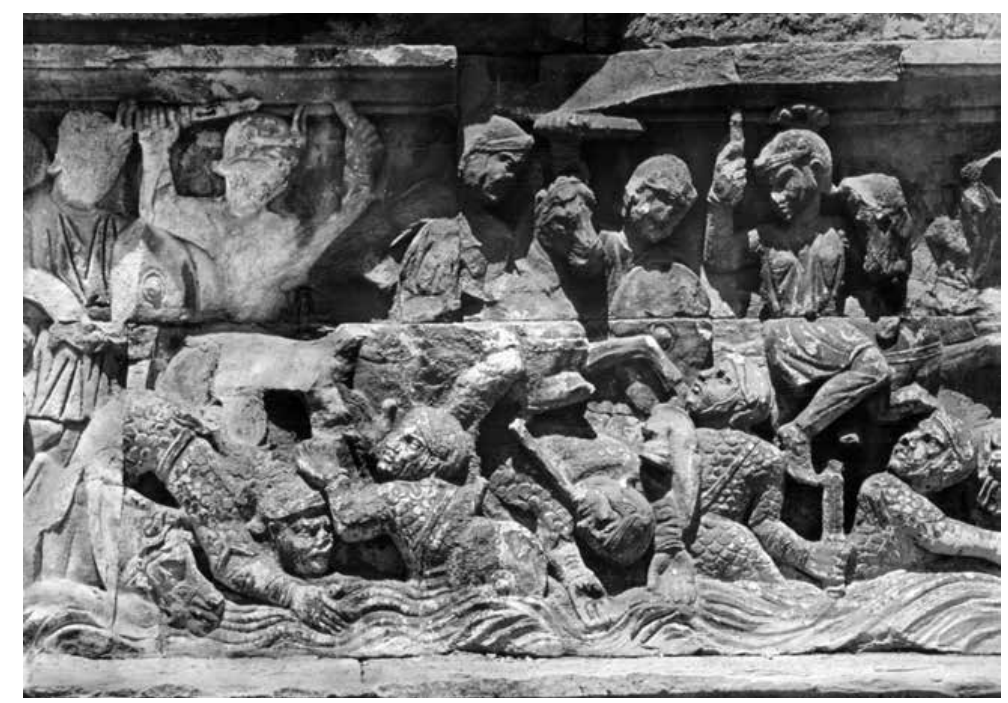

Abb. 13. Rom, Constantinsbogen, Relief, Detail Angreifer und Besiegte, Proelium apud Tiberim, aus: Antonio Giuliano: Arco di Constantino, Mailand 1955, Abb. 38 r. o. 


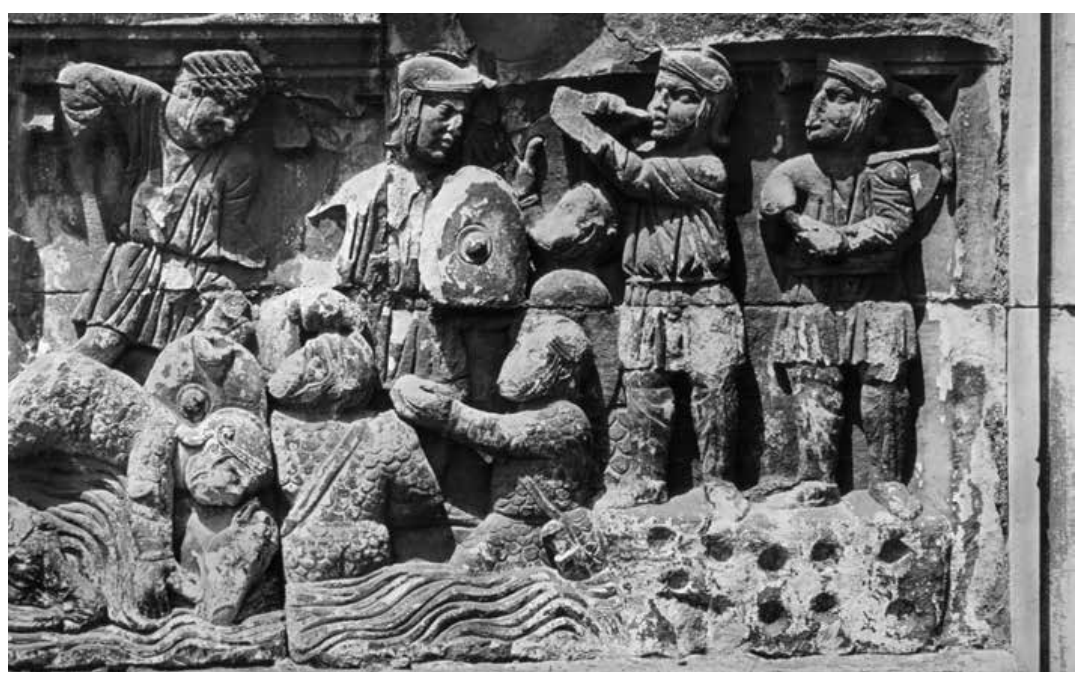

Abb. 14.: Rom, Constantinsbogen, Relief, Detail Angreifer und Besiegte, Proelium apud Tiberim, aus: Antonio Giuliano: Arco di Constantino, Mailand 1955, Abb. 38 r. u.

sich dadurch die Ordnung der Besiegten in oder knapp über den Wellen des Flusses und in der oberen Ebene preschen die Sieger - Reiter wie Fußtruppen nach vorne, aus dem Reliefgrund heraus. Die angreifenden Truppen bestehen aus den Truppen des Obsidio-Frieses: Den bogenschießenden maurischen Auxiliareinheiten, hier in langärmeligen Tunicae und Bracae, den ebenfalls zu Fuß kämpfenden Cornuti und zum Teil berittenen Soldaten des Typus, wie er auf bei der Belagerung zwischen dem linken Cornutus-Offizier und den beiden ersten Angreifern dargestellt ist; die Gewandung und Rüstung der beiden letztgenannten Typen entspricht ausdrücklich nicht der Obsidio, bewaffnet sind die Sieger mit Speer oder Schwert und Schild, tragen jedoch den attischen Helm und keinerlei Rüstung. ${ }^{123}$

Die besiegten Truppen des Maxentius - entweder Reiter oder Fußsoldaten tragen ebenfalls langärmelige Tunicae, die Bracae, Schuhe und einen bis an die Knie reichenden, an der Hüfte gegürteten und geschlitzten Schuppenpanzer; wie die Angreifer tragen sie den attischen Helm; deutlicher kann man die victoria civilis nicht darstellen. ${ }^{124}$ Die Verlierer tragen kurze Schwerter an dem über die rechte Schulter gelegte Schwertgehenk und einen kleinen Rundschild mit Umbo ${ }^{125}$ Der Schuppenpanzer kann als Indiz dafür gesehen werden, dass es sich bei den Besiegten um Angehörige der Prätorianergarde handelt, wenn man das trajanische Relief auf dem Attikageschoss der westlichen Schmalseite

123. L'ORANGE, Der spätantike Bildschmuck, 68. 


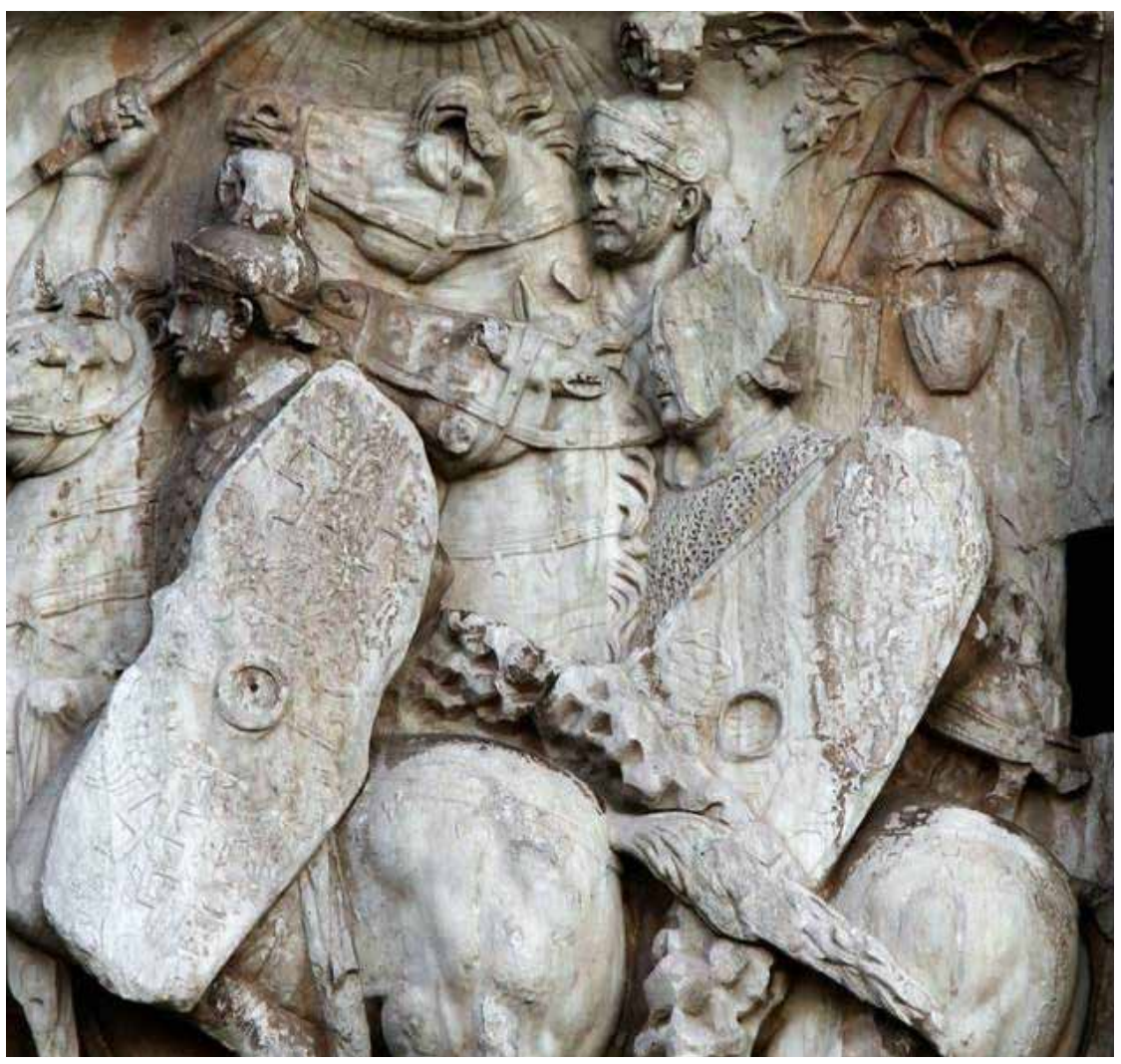

Abb. 18.: Rom, Constantinsbogen, Relief des Attikageschosses der westlichen Schmalseite, trajanisches Relief, Kampfszene, Fotografie: William Storage

hinzuzieht: Bei den Reitern der Kampfdarstellung handelt es sich eindeutig um Praetoriani, das gibt der Skorpion auf dem Schild des linken Reiters zu erkennen [Abb. 18].126 Helm, Bewaffnung und Rüstung der dort dargestellten Soldaten entsprechen denen der Besiegten auf dem Proelium-Relief; wegen der zahlreichen Pferde könnte es sich wohlmöglich um die Equites Singulares Augusti handeln. ${ }^{127}$

Die Darstellung des Kampfes ist äußerst dynamisch und zeigt dabei die gnadenlose Metzelei unter den besiegten Truppen des Maxentius: Rechts neben der Victoria stürzt ein Reiter in den Fluss und wird dabei von einem Speer 40,76

126. Sandra Bingham: The Praetorian Guard. A History of Romes Elite Special Forces, New York 2013,

127. L'Orange, Der spätantike Bildschmuck, 48-49. 
durchbohrt, daneben hebt ein Cornutus zum Hieb gegen einen offensichtlich waffenlosen und durch einen Speer verwundeten Soldaten an, dessen Hände um Gnade ersuchen. Selbst den zur Flucht gewandten Feinden setzen die Sieger mit Waffengewalt nach, und die Bogenschützen sind dabei, gegen die ertrinkenden Verlierer ihre Pfeile abzufeuern [Abb. 3 und 14]. ${ }^{128}$ Bedenkt man, dass es sich dabei um eine victoria civilis handelt, wirkt das Maß an Gewalt, das hier von römischen Truppen gegen Römer angewandt wird, erstaunlich; dieser Eindruck verstärkt sich noch, eingedenk der Tatsache, dass es sich bei den siegreichen Truppen auch um gallische und maurische Verbände handelt, die über die stadtrömischen Kohorten und selbst die Prätorianergarde siegen. Auch dieser Umstand wird für die folgenden Ausführungen von Bedeutung sein. Den Exkurs abschließend bleibt festzuhalten, dass wie bei dem ObsidioFries auch die Darstellung der Proelium-Fries die Entrückung des Kaisers aus dem Kampfgeschehen zeigt, doch noch wesentlich deutlicher: Der Kaiser steht als einziger auf dem Schiff, bereit auf das gegenüberliegende Ufer überzusetzen, dabei ist er umgeben von drei Götterfiguren, die ihn gänzlich von dem Kampfgeschehen abschirmen und eine räumliche Trennung zwischen der soldatisch-kämpferischen Dimension der Szenerie und seiner kaiserlichen Erhabenheit liefern.

\section{Zur Deutung des Frieses der Proelium apud Tiberim}

Um einen Vergleich mit den Auffälligkeiten hinsichtlich der Variation der Darstellung des Obsidio-Frieses mit dem Panegyricus des Jahres 313 anstellen zu können, soll zuvorderst die Passage zum Kampf bei der Milvischen Brücke herangezogen werden; sie lautet wie folgt:

„Doch der göttliche Geist und die unvergängliche Majestät der Stadt selbst haben den Verbrecher seiner Klugheit beraubt, so dass er aus jener alten Erstarrung und dem so schändlichen Schlupfwinkel unversehens hervorbrach [...] Doch wie hat er sein Heer zur Schlacht aufgestellt, der Sklavenwicht, der so viele Jahre schon den Purpur trug? Ganz und gar so, dass niemand entkommen konnte und niemand, der, wie es geschieht, vom Platz gedrängt ist, einen Schritt zurücksetzen und den Kampf von neuem beginnen konnte, da er von vorn durch deine Kriegsmacht bedrängt, im Rücken durch den Tiber festgehalten wurde. [...] Beim ersten Anblick deiner Majestät also und beim ersten Angriff deines so viele Male siegreichen Heeres gerieten die Feinde in Schrecken und wurden in die Flucht geschlagen und durch die Engstelle des Pons Mulvius von ihrem Fluchtweg abgeschnitten: mit Ausnahme der ersten Anstifter jenes Räuberbandenkrieges, die, ohne Hoffnung auf Gnade, den Platz, den sie für den Kampf gewählt hatten, mit ihren Leibern bedeckten, stürzten sich die übrigen alle jählings in den Fluss, so dass es schließlich zu einer Verkürzung des 
Gemetzels für die erschöpften Hände deiner Soldaten kam. Als der Tiber die Frevler verschlungen hatte, riss eben dieser Tiber auch jenen selbst, auf seinen vergeblichen Versuch hin, mit seinem Ross und seinen auffallenden Waffen über die Steilhänge des jenseitigen Ufers zu entkommen, in einen Strudel und zog ihn in die Tiefe hinab. ${ }^{\text {"129 }}$

Nach den Erfolgen der oberitalischen Kampagne und nach der logistischen Vorbereitung zog Constantin im Herbst des Jahres 312 mit seinen Truppen entlang der Via Flaminia nach Rom, um Maxentius' Herrschaft zu beenden. ${ }^{130}$ Vor den Toren der Stadt und nach einigen Gefechten entlang der Marschroute kam es bei der Milvischen Brücke zur Entscheidungsschlacht. ${ }^{131}$ Maxentius wartete nicht die Belagerung ab, sondern stellte sich dem Herausforderer mit einem etwa gleichstarken Heer auf offenem Feld entgegen. ${ }^{132}$ Schließlich verlor er Schlacht und Leben, dies ist die Situation, die uns der Fries zeigt. ${ }^{133}$ Die Schlacht spielte sich am rechten Ufer des Tibers oberhalb des zerstörten pons ab, nachdem eine Vorhut des maxentianischen Heeres bereits zuvor möglicherweise bei Saxa Rubra - durch Constantins Truppen aufgerieben worden war. ${ }^{134}$ Sodann rückte das constantinische Heer - allen voran die Reiterei - in breiter Aufstellung auf die Stellung des Maxentius vor, wobei vor allem die Prätorianer die wichtigste Verteidigungslinie vor dem Tiber darstellten. Mit dem Rücken zum Fluss gewandt, zwangen die leichter gerüsteten Truppen Constantins die gepanzerten Feinde in die Fluten des Flusses; auch dies lässt der Fries erkennen. Laut unseren Quellen ist es nicht unwahrscheinlich, dass Maxentius beim Herannahen des Feindes die Milvische Brücke abbrechen ließ - wie auf dem Fries dargestellt -, um eine von ihm errichtete hölzerne Behelfsbrücke zu seinem eigenem Vorteil zu nutzen. Davon könnte der Pfeiler rechts vor dem kaiserlichen Schiff zeugen. Zosimos berichtet uns darüber:

„Indem beide Gegner mit dieser Kriegsmacht gerüstet waren, schlug Maxentius eine Brücke über den Tiber, welche jedoch nicht von demjenigen Ufer, das gegen die Stadt lag, bis an das andere ununterbrochen zusammenhing, sondern in zwei Teile dergestalt zertrennet war, dass mitten auf dem Strom eiserne Haken aneinander eingehängt waren, die jedes Mal auseinander genommen wurden, so oft man die Brücke nicht vereinigt haben wollte. Hierauf befahl er den Bauleuten, sobald sie Konstantins Heer auf dem Vereinigungspunkte der Brücke sähen, die Haken zu öffnen und die Brücke zu trennen, damit alle,

129. Paneg. Lat. 12, 16, 2-3; 17, 1-2. (Übers. Müller-Rettig).

130. Sснміт , Leben und Herrschaft, 150-151.

131. Laut Aurelius Victor, Caes. 40, 23 fand die Schlacht bei Saxa Rubra statt, einem Engpass der Via Flaminia. Allerdings kann dies auch so zu verstehen sein, dass der Kampf dort begonnen hatte und sich dann bis an dem Tiber erstreckte.

132. Sснміт T, Leben und Herrschaft, 152-153.

133. Die Frage, warum Maxentius die Sicherheit der römischen Mauern verlassen hat, hat die constantinische Propaganda mit dem Wirken göttlicher Mächte und dem Wahnsinn des Usurpators begründet: Paneg. Lat. 12, 14, 3; 16, 1-2; Eus. hist. eccl. 9, 9, 1-4; Lact. mort. pers. 44, 8-9; Zos. hist. 2, 16, 1. 134. Sснміт , Leben und Herrschaft, 153. 
die auf derselben stünden, in den Fluss stürzten. Diese List hatte Maxentius ersonnen! “"135

Große Teile der maxentianischen Truppen wandten sich aus dem taktischen Rückzug heraus nun zur Flucht und dabei scheint die Behelfsbrücke ihnen zum Verhängnis geworden zu sein. ${ }^{136}$ Maxentius ertrinkt beim Versuch des Rückzuges ebenso wie ein großer Teil der ihm ergebenen Praetoriani, und die constantinischen Truppen setzen den Besiegten mit aller Härte nach - auch davon zeugt der Fries in aller Deutlichkeit. Damit ist die Schlacht entschieden, dies belegt die Victoria, die abermals daran ist, dem Kaiser den Lorbeer auf das Haupt zu setzen; dieser setzt ob der zerstörten Brücke mit dem Schiff auf das andere Ufer über. Bild- und Textquelle sind diesmal erstaunlich dicht beieinander, auch bei der für diese Untersuchung so wichtigen Frage, wie der Kaiser am Geschehen beteiligt wird: Erinnern wir uns an den Proelium-Fries, so fiel auf, dass die Götter-Kaiser-Gruppe sehr deutlich dem Schlachtengetümmel entrückt ist. Dies findet sich ebenso im schriftlichen Bericht, wonach schon das Erscheinungsbild des Kaisers den Mut der Feinde bis zur Flucht sinken ließ; von einem blutverschmierten, selbst in den Kampf eingreifenden Kaiser weiß der Panegyricus nichts zu berichten. Einzig in Nazarinus' Panegyricus von 321 liest man von dem persönlichen Eingreifen des Kaisers, mit goldenem Helm und Schild auf seinem Pferd; doch entspräche dies den tatsächlichen Umständen, dann hätte wohl auch der Lobredner von 313 für die Schlacht an der Milvischen Brücke ein solches Eingreifen berichtet, schließlich ist der Verona betreffenden Passage trotz aller Betonung der Gefahr für Kaiser und Reich eine deutliche Bewunderung des persönlichen Eingreifens Constantins zu entnehmen. ${ }^{137}$

Diese Passage abschließend lässt mit einiger Bestimmtheit festhalten, dass Constantin an der Schlacht bei pons Milvius nicht persönlich eingegriffen hat und der Fries den tatsächlichen Höhepunkt der Schlacht angibt. ${ }^{138}$ Aus dem

135. Zos. hist. 15, 6-7, zitiert nach: Geschichte des Zosimus. Erster Band und zweiter Band. Aus dem Griechischen zum Erstenmale übersetzt und mit Anmerkungen begleitet von Seybold und Heyler. (Sammlung der neuesten Übersetzungen der Griechischen prosaischen Schriftsteller 10), Frankfurt am Main 1802, 147.

136. Dazu berichtet uns Eus., vita Const. 2, 15: „So lösten sich nach Gottes Willen die Maschinen der Brücke, die das Verderben bargen, nicht zur gehofften Zeit, es senkte sich die Brücke und die Schiffe versanken zumal samt der Mannschaft in die Tiefe, und zwar zu allererst der unselige Tyrann selber, dann auch seine Leibwache und seine Trabanten, wie es das Wort Gottes vorherverkündet hatte: „Sie sanken wie Blei in dem gewaltigem Wasser", zitiert nach: Des Eusebius von Cäsarea ausgewählte Schriften. Aus dem Griechischen übersetzt von P. Johannes Maria Pfättisch und Dr. Andreas Bigelmair. (Bibliothek der Kirchenväter, 1. Reihe, Band 9) München 1913, 187.

137. Paneg. Lat. 4, 29, 5-6.

138. Bei Ammian lesen wir deutlich von der Position des Befehlshabers bei einer Schlacht, Amm. 31, 13, 8-9: „Dumque omnes dispersi per ignotos tramites cedunt, imperator diris pavoribus circumsaeptus paulatimque insiliens funerum moles, ad Lancearios confugit et Mattiarios: qui, dum multitudo tolerabatur hostilis, fixis corporibus steterant inconcussi. eoque viso Traianus exclamat spem omnem absumptam, ni desertus ab armigeris princeps saltim adventicio tegeretur auxilio. hocque audito Victor nomine comes Batavos in subsidiis locatos haut procul ad imperatoris praesidium raptim cogere properans cum invenire neminem posset, gradiens retro discessit, parique modo Richomeres periculo semet exemit et Saturninus." 
Gesagten ergibt sich die bemerkenswerte Einsicht, dass der recht gut über das Schlachtgeschehen informierte Künstler, der den Höhepunkt der Schlacht an der Milvischen Brücke realitätsnah aus dem Marmor gearbeitet hat, bei der Darstellung der Schlacht um Verona - von der angenommen werden darf, dass er über sie ebenso gut im Bilde war - einer ganz anderen Darstellungsabsicht unterlag. Dieser Sachverhalt bestärkt die Frage nach den Ursachen dieser Entscheidung, die in Anbetracht der ausgeklügelten ideologischen Botschaft des Bogens kaum willkürlicher Natur sein dürfte.

\section{Die Darstellung Kaiser Constantins auf dem arcus Constantini}

Bei der Frage nach der Motivation einer solchen Darstellung, wie der des Kaisers auf dem Obsidio-Fries, bietet sich eine Reihe von möglichen Antworten an, die wohl kaum voneinander zu trennen sind und daher auch zusammenfassend behandelt werden:

I. Es handelte sich bei dem Sieg über Maxentius um einen Sieg ex sanguine romano und die Darstellung eines Kaisers, der persönlich römische Bürger erschlägt, wäre für einen Ehrenbogen an solch exponierter Stelle äußerst fragwürdig.

II. Die dargestellte Entrückung des Kaisers aus dem Kampfgeschehen, dessen Wohlergehen auf das Engste mit dem salus publicae verbunden ist, ergibt sich aus den Erfahrungen der Reichskrise des 3. Jahrhunderts. Erst zwei Generationen zuvor hatte Rom die demütigende Gefangennahme Kaiser Valerians durch den Sassanidenherrscher Shapur im Jahre $260 \mathrm{zu}$ verkraften, wovon bis heute das Triumphrelief im iranischen Naqsch-e Rostam zeugt.

III. Die Kaiserfigur des Obsidio-Frieses ehrt die imperatorische Größe des Kaisers - auch dies kann die Enormität der Figur anzeigen -, aufgrund derer die Schlacht um Verona entschieden worden ist: Nicht die Kampfhandlungen selbst, sondern die glückliche Taktik ihres Befehlshabers hat die constantinischen Truppen vor den Mauern Veronas siegen lassen.

IV. Constantin konnte sich auf den Friesen seines Ehrenbogens ausschließlich als überlegener Feldherr in Szene setzen lassen, da er durch die Übernahme trajanischer Spolien bereit die virtus militis für sich in Anspruch nehmen konnte.

V. Die Darstellung des Kaisers, entrückt aus der Welt der Sterblichen bzw. des menschlichen in göttliche Sphären, entspricht der durch Diocletian vorgenommenen Sakralisierung des römischen Kaisertums; vor diesem Hintergrund wird auch die Kampfdarstellung des Kaisers auf dem Obsidio-Fries erklärbar: Ein göttlich berührter Kaiser konnte kaum 
wie seine Soldaten an vorderster Front kämpfen, sondern musste dem Geschehen fern bleiben. Dies entspricht der spätantik-diocletianischconstantinischen Kaiserideologie.

Der Triumph Constantins, den sowohl der Bogen als auch der Panegyricus von 313 ehren, bestand in dem siegreichen Feldzug gegen Maxentius; dass es sich dabei um einen Bürgerkrieg handelte, war jedem Betrachter und Hörer klar. Dass ein solcher Sieg nicht wie eine victoria über fremde Völker verherrlicht werden konnte, liegt auf der Hand. Der Constantinsbogen ist das erste Monument in der Geschichte der römischen Kaiserzeit, das in aller Deutlichkeit eine victoria civilis ehrt; dass die staatliche bzw. kaiserliche Repräsentationskunst dieser einmaligen Situation Rechnung tragen musste, ist ebenso einleuchtend.

Einleitend ist bereits auf die Inschrift und die Intention des Ehrenbogens eingegangen worden: Der arcus Constantini bezeugt die triumphalen Taten des Kaisers, sein triumphierendes Kaisertum, nicht jedoch einen expliziten Sieg. Dieser Tatsache entspricht die Schilderung des Panegyricus, der die clementia des Kaisers während seines Feldzuges lobt; so habe Constantin den feindlichen Soldaten in Susa Amnestie versprochen, sollten sie sich ihm unterwerfen, und selbst als in Turin die maxentianischen Verbände sich ihm aus Rache für seinen vorherigen Sieg entgegenwarfen, habe er nur die Soldaten, nicht jedoch die incolae bestraft. ${ }^{139}$ In Verona habe die feindliche Armee die Stadt drückend besetzt mit acerrimi duces und pertinacissimus praefectus, doch Constantins Qualität als Feldherr und seine kluge Berechnung (animi magnitudo) hätte der zahlenmäßig unterlegenen Truppe den Sieg beschert und die Stadt sowie ihre Einwohner befreit. ${ }^{140}$ In der Tat wurde die Schlacht um Verona nicht mit Waffen, sondern mit einer gelungenen Taktik entschieden; die magnitudo mentis der Inschrift könnte auch darauf bezogen werden und sie liefert gleichermaßen einen möglichen Grund für die zurückgenommene Darstellung des Kaisers auf dem Obsidio-Fries: Die unbewegt-passive Darstellung der Kaiserfigur auf den constantinischen Schlachtenfriesen ließe sich zumindest auch mit dem Hinweis auf seine Geistesgröße als Befehlshaber erklären, der sich nicht, wie auf den trajanischen Friesen, in den Kampf stürzt, sondern dessen Truppen seine Befehle aufgrund seiner auctoritas voller Überzeugung und Entschlossenheit durchsetzen.

Darüber hinaus ist ein weiterer Faktor zu bedenken: Am Ende der Schlacht - so der Lobredner von 313 - hätten Constantins Offiziere ihn mit blutigen Händen und außer Atem vorgefunden, wobei sich - auch dies wurde gezeigt - eine gewisse Bewunderung der kaiserlichen virtus bei dessen persönlichem Eingreifen in den Worten des Lobredners äußert. ${ }^{141}$ Doch

139. Paneg. Lat. $12,2,1 ; 5,4-10,5$.

140. Paneg. Lat. $12,8,1-10,5$.

141. Paneg. Lat. 12, 9, 3-6. 
war der Umstand, dass römische Soldaten durch die Hand constantinischer Truppen - im schriftlichen Bericht sogar durch den Kaiser selbst - ihr Leben verloren, keineswegs unproblematisch: Der Lobredner kam nicht umhin, den vernichteten Truppen des Maxentius ihre Romanitas abzusprechen, wenn er schreibt, sie seien einst Römer gewesen, doch mit der Gefolgschaft für den Usurpator hätten sie diese eingebüßt. ${ }^{142}$ Maxentius selbst sei ein monstrum und Schandfleck (dedecus) gewesen, und hätte der superstitio, der Gier sowie der Grausamkeit Tür und Tor geöffnet; nicht zuletzt seien auch seine Truppen von dessen Fehlern korrumpiert gewesen, weshalb sie für die von ihnen besetzten Städte eine bedrückende und habgierige Last (avaritia) bedeutet hätten. ${ }^{143}$ Nicht die Usurpation bestimmte die Unrechtmäßigkeit der maxentianischen Herrschaft - dies hätte Constantin, der auf die gleiche Weise nach dem Purpur griff, wohl nur sehr ungern gehört -, sondern ihr durch und durch entarteter Charakter. Mit keinem Wort wird erwähnt, dass Maxentius bereits 308 in Carnuntum zum hostis rei publicae erklärt worden war; dessen bedurfte es nicht. ${ }^{144}$ Vor diesem Hintergrund muss auch die Inschrift auf der Attika gelesen werden, die von iustis armis spricht, die von Constantin gegen tam de Tyranno quam de omni eius factione eingesetzt werden mussten, um - geleitet von göttlicher Eingebung - das salus publicae wieder herzustellen. ${ }^{145}$ Ebenso muss an die Gesamtschau der Spolien gedacht werden: Die trajanischen Statuen der gefangenen Daker auf dem Attikageschoss beispielsweise, oder die beiden Reliefs im Hauptdurchgang, die den triumphierenden und den kämpfenden Trajan zeigen, stellen die persönliche Sieghaftigkeit des Kaisers über fremde Völker dar [Abb. 15, 16 und 17]. ${ }^{146}$

Eingebettet in den spezifischen Hintergrund des Bogens sind sie nicht in erster Linie als Fremde zu sehen, sondern als Begrenzung römischer Freiheit; in diesem Punkt legt sich die Aussage der Spolien wie eine Schablone über die Inhalte des constantinischen Bildwerkes. Dies wird flankiert durch die marc-aurelischen Reliefs auf der Südseite über den constantinischen Schlachtenfriesen: Die Spolien an der Attika zeigen auf der linken Südseite - oberhalb der Obsidio - die Aufnahme externer Feinde unter die römischen Bundesgenossen, während wir auf der rechten Seite - über dem Proelium - die kaiserliche clementia gegenüber den „barbarischen“ Gefangenen erkennen können. ${ }^{147}$ Das Bildprogramm des Bogens unterstreicht damit nicht nur die Rechtmäßigkeit des kaiserlichen Handelns, sondern zugleich auch dessen Besonnenheit und Gnade gegenüber den Feinden. Abgerundet wird dieses ideelle Konstrukt durch die Titel der beiden trajanischen Reliefs im Hauptdurchgang, welche die Kernaussagen des Bogens zusammenfassen:

142. Wienand, Kaiser als Sieger, 241.

143. Paneg. Lat. $12,14,2,5 ; 7,1 ; 17,2 ; 8,1 ; 5,6$.

144. Wienand, Kaiser als Sieger, 241.

145. CIL VI 1139 (p 3071, 3778, 4328, 4340) = CIL VI $31245=$ ILS 694.

146. PRÜCKNER, Konstantins Bilderbogen, 64.

147. PRÜCKNER, Konstantins Bilderbogen, 71. 


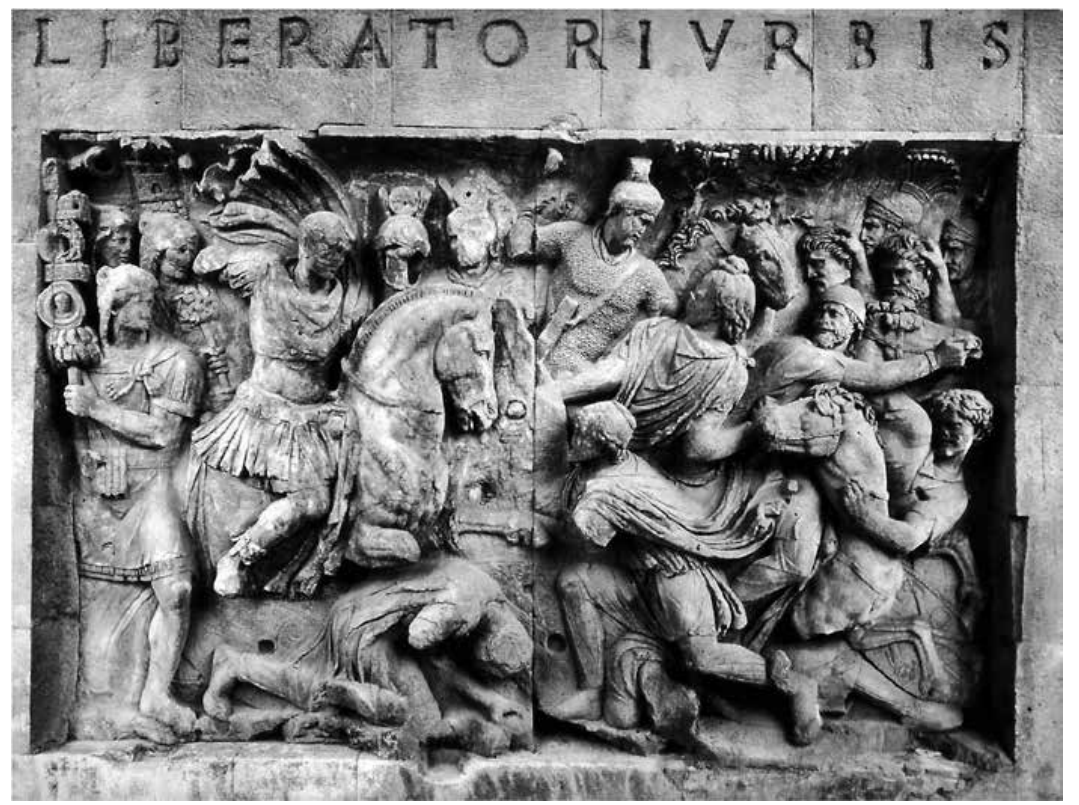

Abb. 15. Rom, Constantinsbogen, Bauplastik, römisch, Original, Marmor, Relief, in situ, Schlachtszene, Trajanischer Fries im Hauptdurchgang, Liberatori Urbis, aus: PAUL ZANKER: Das Trajansforum in Rom als Monument imperialistischer Selbstdarstellung, in: Archäologischer Anzeiger 1970, Abb. 24

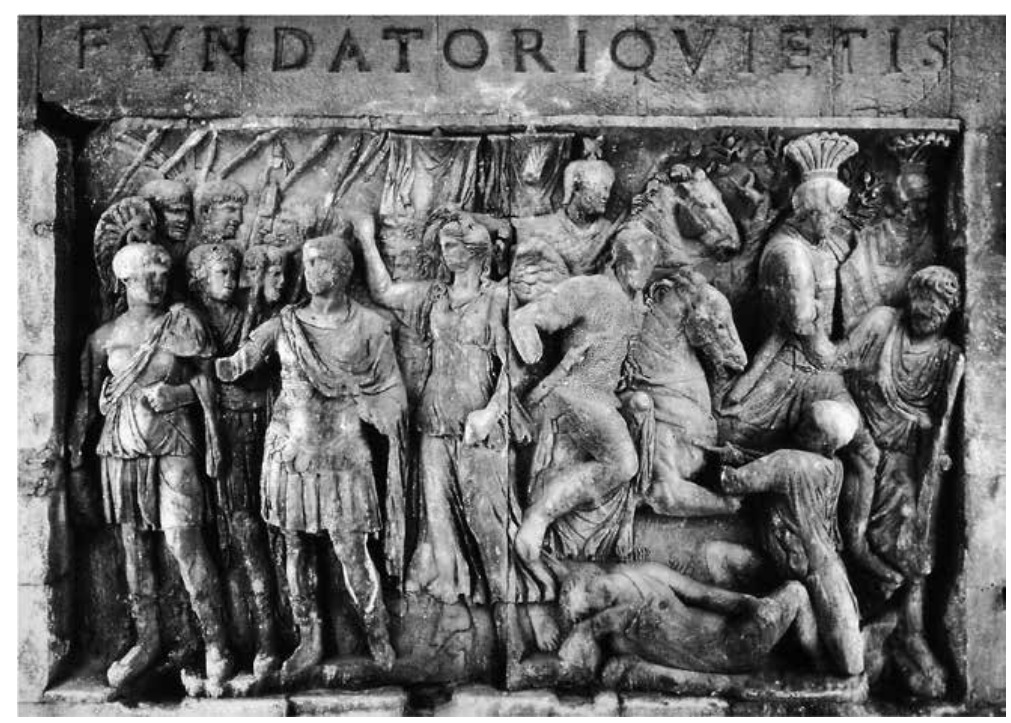

Abb. 16. Rom, Constantinsbogen, Bauplastik, römisch, Original, Marmor, Relief, Schlachtszene, in situ; Adlocutio, Fundatori Quietis; Trajanischer Fries im Hauptdurchgang, aus: Antonio Giuliano: Arco di Constantino, Mailand 1955, Abb. 8 


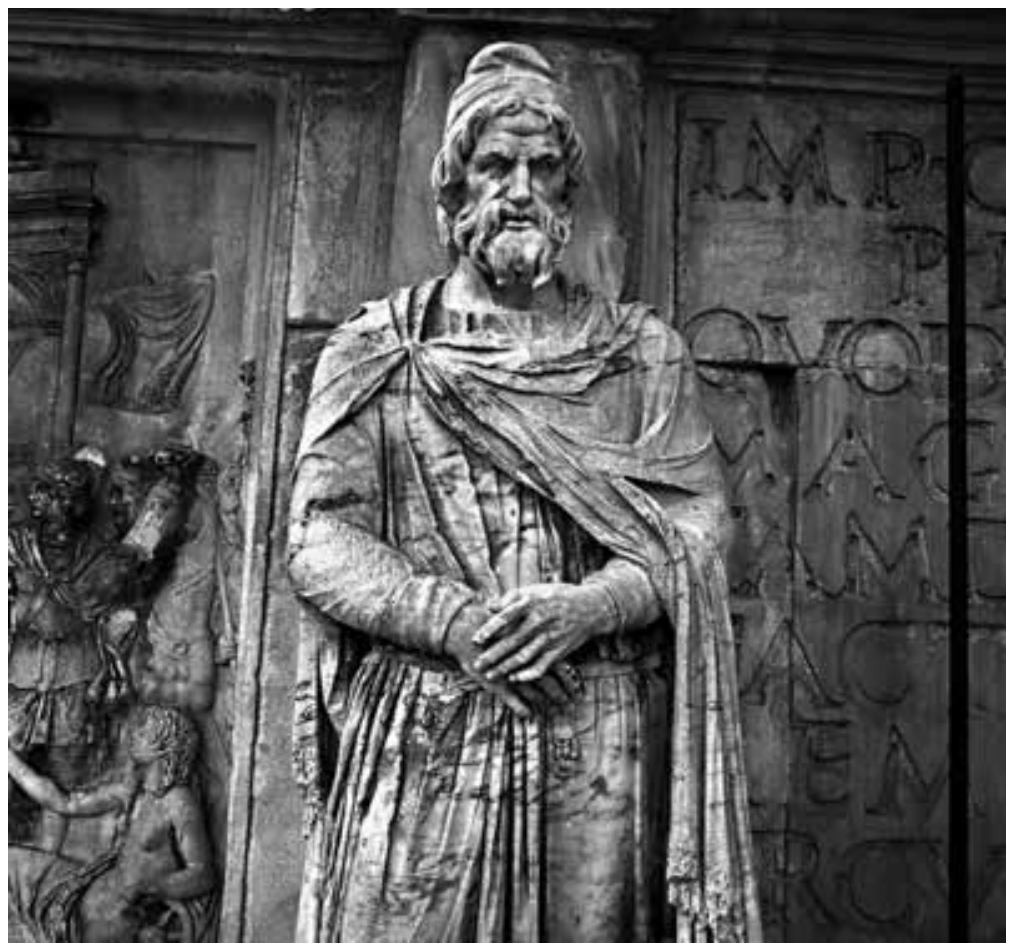

Abb. 17. Rom, Constantinsbogen, Kolossalfigur der Attika, sog. Daker oder Barbar, Gefangenenstatue, Nordseite, Attika, links innen, in situ, aus: Pensabene, P. / Panella, C. (Hrsg.): Arco di Constantino. Tra archeologia e archeometria, Rom 1998, Abb. 24

LIBERATORI URBIS und FUNDATORI QUIETIS; die beiden Inschriften erinnern nicht grundlos an augusteische Panegyrik [Abb. 15 und 16]. ${ }^{148}$ Hinzu kommt, dass Constantin die Gesichtszüge der Kaiserfiguren der Spolien teilweise zu den seinen umarbeiten ließ, womit er sich nicht nur wie ein novus Traianus inszenieren, sondern dessen virtus auch für ihn galt. Constantin avancierte in der Sprache der Spolien zum Korrektiv der zahlreichen Verfehlungen des Maxentius, schließlich hatte dieser sich noch als Conservator Urbis Suae ehren lassen, als Eigentümer Roms also; der Gegensatz zu Constantin als Liberator könnte größer kaum sein. ${ }^{149}$ So wie zwei Jahrhunderte zuvor die taciteische Germanenbeschreibung dazu diente, in der Fremdheit die längst vergangene Romanitas zu beschwören, dient die Fremdheit der Feinde auf den Spolien des Constantinsbogens, um die Herrschaft des Maxentius als ganz und gar unrömisch zu brandmarken; Maxentius und seine Anhänger wurde in der

148. ILs 694-3 = CiL VI 1139. Wienand, Kaiser als Sieger, 242.

149. Christian Ronning: Herrscherpanegyrik unter Trajan und Konstantin, Tübingen 2007, 359 mit Anm. 13. 
Sprache des Bogens zu einem äußeren Feind Roms. Constantins imitatio Traiani ermöglichte es ihm nicht nur, an dessen Siege anzuknüpfen, sondern auch dessen virtus als selbst kämpfender Krieger für sich in Anspruch zu nehmen. In Verbindung mit den beiden untersuchten Friesen ergibt sich die wichtige Einsicht, dass Constantin damit die imperatorische wie auch die soldatische virtus auf sich vereinen konnte: Seine feldherrlichen Qualitäten belegen seine Darstellungen auf dem Proelium-Fries und besonders auf dem Obsidio-Fries, erkennen wir doch bei der letzteren Kaiserfigur den Befehlsgestus in Richtung seiner Truppen. Mit Constantins Gesichtszügen auf den trajanischen Spolien dagegen konnte er sich selbst als Krieger im Schlachtgetümmel inszenieren. In Verbindung mit den Erfordernissen des sorgsamen Umgangs mit der Bürgerkriegsdarstellung konnte Constantin somit beide Herrscherattribute des Befehlshabers und des Kriegers - vertreten, ohne jedoch selbst als Kaiser dargestellt zu werden, der römische Soldaten erschlägt. Daraus ergibt sich, dass eine derartige Darstellung kaiserlicher virtus dazu taugt, die victoria civilis zu relativieren und die Paradoxie der Würdigung eines Sieges über römische Soldaten inmitten Roms zu entschärfen. Hinzu kommt, dass sich nach den Erfahrungen des 3. Jahrhunderts mit seinen unzähligen inneren Konflikten die Inszenierung von Bürgerkriegssiegen mehr und mehr der Semantik äußerer Siege anglich, wobei diese Entwicklung mit dem Constantinsbogen sicherlich einen, wenn nicht den Höhepunkt erfuhr. ${ }^{150}$ Daher widerspricht es auch nicht der inneren Logik der Bildelemente des Bogens, wenn der Kaiser des ObsidioFrieses isoliert vom Kampfgeschehen dargestellt wird, während auf dem Proelium-Fries die siegreichen Truppen den hilflosen, ertrinkenden römischen Soldaten mit aller Härte nachsetzen. Der Panegyriker des Jahres 313 betont sogar die virtus des Kaisers, wenn er berichtet, Constantin habe über die besten Soldaten des Erdkreises gesiegt - das gab deren verwirkte Romanitas noch her -, versehen mit den besten Rüstungen und Waffen und fest entschlossen, den Kampf nicht aufzugeben. ${ }^{151}$ Auch können wir auf den beiden Schlachtenfriesen der Südseite die herausragende Qualität der maxentianischen Truppen erkennen, die allesamt in Schuppenpanzer dargestellt worden sind; auf deren mögliche Zugehörigkeit zu den Praetorii wurde bereits hingewiesen. Prägnant formuliert ließe sich sagen, dass Constantins Sieg im Angesicht der herausragenden Qualität seiner römischen Gegner sogar noch aufgewertet wird. Mit dieser constantinischen Siegesinszenierung lassen sich zwei so unvereinbare Überlegungen, wie der bewussten Zurückhaltung der Kaiserfigur der Obsidio und das blutige Gemetzel an römischen Soldaten - vor allem durch gallische Kerntruppen und maurische Auxilia (!) - auf dem Proelium-Fries schlüssig erklären: Die Kampfdarstellungen des Constantinsbogens sind von den Spolien nicht zu trennen. Die Fragwürdigkeit der Darstellung besiegter und sterbender römischer Soldaten auf den constantinischen Schachtfriesen, 
noch dazu an dem herausragenden Standort des Bogens, kann, eingebettet in das bildlich-kommentierende Programm des Bogens, tatsächlich abgemildert und sogar positiv beladen werden. Dies zeigte die Betrachtung der Kaiserdarstellungen der beiden Schlachtenfriese an der Südseite des Bogens sowie deren Vergleich mit den Schilderungen des Panegyricus von 313. In der Gesamtschau des Monumentes offenbart sich schließlich eine genuin constantinische Triumphideologie, der es gelingt, die victoria civilis als ehrwürdiges Ereignis in Szene zu setzen, wenngleich nicht unverhohlen als eine solche, so doch in Äquidistanz zu externen Siegen.

Schließlich muss ein weiterer Faktor in dieÜberlegungen einbezogen werden, der ebenfalls eine schlüssige Erklärung für die Passivität der Kaiserfigur auf den constantinischen Frieses leisten kann: Die römische Kaiserideologie hatte sich im Laufe des dritten und vierten Jahrhunderts grundlegend verändert. Während es für den primus inter pares notwendig war, den Anschein der Gemeinsamkeit zu wahren, war das Gegenteil für die spätantiken domines der Fall; die republikanische Repräsentation des Prinzipates taugte nicht mehr für die monarchistische Verfassung des spätantiken Imperium Romanum. Dieser Wandel lässt sich ebenfalls in den Aussagen des Trierer Lobredners erkennen, sie lauten folgendermaßen:

„Was hast denn du, Imperator, mit dem Schicksal des geringeren Standes zu tun? Für diejenigen ist es angemessen zu kämpfen, die, wie es jedem einzelnen vom Geschick beschieden ist, entweder siegen oder fallen müssen: du, von dessen Leben die Geschicke aller abhängen, solltest irgendein Risiko eingehen? Dich inmitten so vieler Geschosse und Schwerter bewegen? Wer verlangt so etwas von dir? Oder wer könnte es zulassen, dass den Wechselfällen des Krieges irgendein Zugriff auf dich zustünde? Schickt es sich etwa für dich, Imperator, den Feind niederzustechen? Im Gegenteil, es schickt sich nicht einmal, dich anzustrengen." ${ }^{152}$

Nicht einmal anstrengen soll sich der Kaiser; mit diesem Hinweis steht der Panegyriker ganz auf dem Fundament spätantiken Kaisertums, wie Diocletian und Constantin es geprägt haben. Die Sakralisierung des Kaisertums - die tetrarchische Bezugnahme auf Iovius und Herculius bzw. mit Constantin auf Sol und Christus - war nach der enormen Zahl an Usurpationen des 3. Jahrhunderts notwendig geworden, um die dynastische Erbfolge bzw. einen zu leichten Zugriff auf das Kaisertum als Krisenfaktor endgültig zu disqualifizieren. Nur die Zugehörigkeit zur domus divina, die ausdrücklich nicht dem dynastischen Prinzip unterlag, konnte die Herrschaft als Caesar und Augustus legitimieren. ${ }^{153}$ Auch der Wandel des höfischen Zeremoniells zugunsten der Übernahme orientalischer Riten, wie beispielsweise der Proskynese in Form der römischen adoratio, die Anrede als dominus, die 
rituell verhüllten Hände und das zeremonielle Schweigen im Beisein des Kaisers, belegt die ideologische Untermauerung des monarchistisch-göttlichen Charakters spätrömischer Kaiserherrschaft. ${ }^{154}$ Das tetrarchische Kaisertum als Amt per se war etwas Göttliches, die Amtsinhaber selbst galten als electi und besonders von der göttlichen Sphäre berührt. ${ }^{155}$ Die Herrschaft einer solchen kaiserlich-göttlichen Familie - der zwei Augusti und zwei Caesares - konnte in ihrer Legitimität normativ nun nicht mehr durch Usurpationen in Frage gestellt werden; das römische Kaisertum wurde damit regelrecht unantastbar. Diesem Sachverhalt entsprachen nun auch die Modalitäten des kaiserlichen Zeremoniells und der kaiserlichen Repräsentation; der Kaiser wurde dem irdisch-menschlichen Bereich entrückt und war fortan eher divus als Mensch. ${ }^{156}$ Dass auch die kaiserliche Repräsentationskunst davon keine Ausnahme machte, ist nachvollziehbar. Dementsprechend wird auch der obige Kommentar des Panegyricus verständlich, wenn er den Kaiser ermahnt, sich seiner exponierten Stellung, seiner sacrosanctitas gewahr zu sein, und nicht unter den einfachen Soldaten am Kampf teilzunehmen. Schließlich wird auch dieser Faktor zu berücksichtigen sein, will man die zurückgenommenpassive Darstellung des Kaisers auf den beiden Schlachtenfriesen erklären und auch, warum auf dem Obsidio-Fries der Kaiser, anders als in dem schriftlichen Bericht, derart isoliert dargestellt wird.

\section{Abschliessende Bemerkungen}

Im Verlauf der vorangestellten Überlegungen wurde gezeigt, dass die Darstellung des Kaisers auf den beiden constantinischen Schlachtenfriesen des Triumphbogens ganz den Modalitäten spätantik-kaiserlicher Repräsentation entspricht. Schon seit der frühen Kaiserzeit gehört die virtus zum Tugendkatalog der römischen Kaiser. ${ }^{157}$ Dass deren Verbildlichung auf einem Triumphbogen nicht fehlen darf, liegt schon in der Natur des Monumentes begründet. Der Kaiser wird auf beiden Friesen als passiver Schlachtenlenker dargestellt, dem menschlich-soldatischen Bereich entrückt. Unter Bezugnahme auf die schriftlichen Quellen konnte gezeigt werden, dass die Kaiserdarstellung des Obsidio-Frieses dem Panegyricus von 313 hinsichtlich des Höhepunktes des Kampfgeschehens sogar widerspricht. Dies lässt sich erklären durch die besondere Herausforderung der Darstellung einer victoria civilis, die Sakralisierung des spätantiken Kaisertums und die Einbettung der constantinischen Friese in den besonderen Spolienkontext des arcus Constantini. Die virtus-Vorstellung eines kämpfenden Kaisers hatte sich

154. KolB, Herrscherideologie, 21, 40-41.

155. Ebd. 36

156. Ebd. $36-49$.

157. Carl Joachim Classen: «Virtutes Romanorum. Römische Tradition und griechischer Einfluß», in: Gymnasium (95) 1988, 293-294. 
von der Beteiligung des Princeps - zu denken wäre etwa an den trajanischen Fries im Hauptdurchgang des Bogens [Abb. 15] - hin zu dem Ideal des sakronsankten spätantiken Imperators gewandelt. Die Kaiserideologie der Spätantike war mit einem primus inter pares auf dem Schlachtfeld gänzlich inkompatibel. Der dominus der späten Kaiserzeit konnte als divus praesens, als ein göttlich erwählter Garant der Sicherheit und Kontinuität des Reiches, nicht unter Gleichen sein; eben auch nicht auf dem Schlachtfeld. Dieser Tatsache trägt der Constantinsbogen nicht nur mit seiner ausgeklügelten politischen Botschaft Rechnung, sondern auch durch die besondere Darstellungsform des Kaisers auf den constantinischen Schlachtenreliefs. Dabei spiegelt der Constantinsbogen die Ideale des spätantiken Kaisertums wider wie kaum ein anderes Monument. Nicht nur die genuin constantinische Triumphideologie macht den Bogen zu einem bemerkenswerten Beispiel spätantiker Repräsentationskunst, sondern auch seine vielschichtige Darstellung des Kaisertums constantinischer Prägung. DieIsolation des Kaisers, seine göttlichen Begleiter und die enorme Größe der Kaiserfiguren der beiden Schlachtenfriese an der Südseite des Bogens sind dabei nicht als bloßer Ausdruck des Wandels spätrömischer Kaiserideologie zu verstehen, sondern als maßgebend für die gesamte römische Repräsentationskunst. Und wenngleich der Constantinsbogen oft als Beleg eines vermeintlichen künstlerischen Niedergangs hat herhalten müssen, so kann man sich nur schwerlich der Einsicht verschließen, dass der besondere Stil und die spezifische Komposition des Monumentes Ausdruck der Notwendigkeit einer überfälligen Anpassung der Darstellung des spätantiken Kaisertums sind. ${ }^{158}$ Insofern geht man nicht fehl in der Annahme, dass der Constantinsbogen nicht nur für den Geehrten selbst ein zukunftsweisendes Ehrenmonument dargestellt haben dürfte, sondern für das spätantike Kaisertum selbst.

158. Jacob Burckhardt kam zu folgender Überzeugung: „Der Constantinsbogen beim Kolosseum ist allerdings ein Werk der Hast und Eile, und dies erklärt und entschuldigt hinlänglich die grosse Roheit der plastischen Ausführung, nicht aber die Hässlichkeit der Gestalten und die Verkümmerung der Züge. Wohl gibt es Zeiten, in welchen die Kunst sich etwas darauf einbildet, ihr Ziel einseitig im Charakteristischen statt im Schönen zu suchen, und jenes sogar bis ins Hässliche zu steigern, ohne dass die den Künstler umgebende Welt daran schuld wäre. Allein hier ist von einer solchen Vorliebe für den Charakter nicht die Rede, sondern ganz einfach von der Unfähigkeit, an den klassischen Schönheitsidealen auch nur oberflächlich festzuhalten, während die Aussenwelt keine Beziehung mehr zu denselben hat." Jaсов BurcKHardT: Die Zeit Constantins des Großen, Bern 1853, ND 1950 Berlin, 255. 